$N^{\circ} 74$

April 2018

Emotional expressions by sports teams: an analysis of world soccer player portraits

Astrid Hopfensitz César Mantilla 


\title{
EMOTIONAL EXPRESSIONS BY SPORTS TEAMS: AN ANALYSIS OF WORLD CUP SOCCER PLAYER PORTRAITS
}

\author{
Astrid HOPFEnSitz (CORRESPONDing Author) \\ TOULOUSE SCHOOL OF ECONOMICS \\ 21 Allee de Brienne \\ 31015 Toulouse, France \\ astrid.hopfensitz@tse-fr.eu
}

\section{Cesar Mantilla}

UNIVERSIDAD DEL ROSARIO, COLOMBIA

cesar.mantilla@urosario.edu.co

\section{forthcoming in Journal of Economic Psychology}

\section{Abstract:}

Emotion display serves as incentives or deterrents for others' in many social interactions. We study the portrayal of anger and happiness, two emotions associated with dominance, and its relationship to team performance in a high stake environment. We analyze 4,318 pictures of players from 304 participating teams in twelve editions (1970-2014) of the FIFA Soccer World Cup, and use automated face-reading (FaceReader 6) to evaluate the display of anger and happiness. We observe that the display of both anger and happiness is positively correlated with team performance in the World Cup. Teams whose players display more anger, an emotion associated with competitiveness, concede fewer goals. Teams whose players display more happiness, an emotion associated with confidence, score more goals. We show that this result is driven by less than half the players in a team.

Keywords: emotions; facial expressions; anger; happiness; contests;

JEL: D91; L83; Z2

Acknowledgements: We would like to acknowledge financial support from the ANR project SINT ANR-15-CE33-0005-01 as well as support through the Institute of Advanced Study in Toulouse (IAST). We are indebted to Paula Zamora for excellent research assistance. We thank Jonathan Stieglitz and Boris van Leeuwen for their useful comments. 


\section{INTRODUCTION}

Psychological mechanisms related to confidence and intimidation are regularly used in conflicts among humans and among other animals. In sports competitions, a modern type of conflict, the aim of these mechanisms is to persuade other contestants of the own superior abilities, like strength, group cohesiveness, or other positive attributes. An extreme example of this behavior is the rugby pregame ritual, the haka dance. The $\mathrm{Ka}$ mate, the specific haka dance performed by New Zealand's rugby teams, is a war dance that has the psychological purpose of demonstrating strength to the in-group and demoralizing the enemy by gestures (Jackson \& Hokowhitu, 2002).

One important dimension in these psychological battles is the expression and perception of emotions. Indeed emotions are in many ways seen as intrinsically linked to sports and sports competitions (Hanin, 2000). While emotion expressions could be seen as a pure byproduct of sports, they are likely to be interpreted by, and thus influential on, opponents and spectators. In this paper we present evidence that soccer teams display specific emotions, outside of a game setting, that are correlated with performance in a high stakes environment. We are further able to differentiate two types of emotional displays: emotions related to aggression and out-group hostility, which we will show to be related to defensive behavior; and emotions related to happiness and confidence, which we will show to be related to offensive behavior.

In our analysis we focus on the display of two emotional traits: anger and happiness. These two emotions have the advantage that their associated facial expressions are considered to be universal (Ekman \& Rosenberg, 1997; Matsumoto \& Willingham, 2006). Both emotional traits are associated with high dominance (Wiggins, Trapnell, \& Phillips, 1988). However anger is associated with low group affiliation, and evokes competitive traits such as arrogance, while happiness is associated with high group affiliation, and evokes more outgoing and confidence related traits such as agreeableness and extraversion (Knutson, 1996). To study emotion display we analyze photo portraits of 4,318 players from 304 teams who participated in the FIFA Soccer World Cup over 44 years, using automated facial recognition software. We further link the emotions displayed by the players in a team, to the teams' performance in the respective World 
Cup tournament. From now on we will use the term "team" to describe a National selection participating in a specific World Cup, and we will use National "squad," to describe a country's National soccer team. ${ }^{1}$

We will focus on the display and thus possible signaling value of emotions, and not on the question how the experience of emotions might be related to performance. Emotion display could be an involuntary sign of an underlying trait of the player, or could be strategically influenced to suggest such a trait. Since we will focus on photographs, selecting specific portraits that display certain expressions, could be done by either the player, the photographer or the agent that selects the final portrait. Since we have only limited information on the precise procedures that lead to the selection of final photographs we can only speculate on the specific underlying mechanisms. However, if some strategic component were in place, we would expect that less successful teams would attempt to imitate the emotion portrayal observed in successful teams. Thus we might expect that, over time, successful teams will adjust or fine-tune their signal to be not confused with imitators.

The literature on signals used in sports has discussed 'cheap talk' type of signals as well as signals linked to physiological traits. An example of the first is the literature focusing on the display of certain colors (Attrill, Gresty, Hill, \& Barton, 2008; Hill \& Barton, 2005; Ioan et al., 2007; Krenn, 2014). However, no robust empirical evidence for an advantage of displaying for example the color red has been observed (Fortunato \& Clauset, 2016). Good examples of morphological and physiological traits are signs of strength. Strength can be easily deduced from size, bulk or shoulder-width. More generally, testosterone and other hormones are related to better performance in sports (Wood \& Stanton, 2012), with testosterone being also linked to dominance and aggression (Mazur \& Booth, 1998). Predisposition toward aggression might be a valuable feature in high performance sporting competitions. Selection on aggressiveness is evidenced in traits associated to masculinity, such as the larger facial width-to-height ratio for professional hockey players compared to students (Carré \& McCormick, 2008; Carré, McCormick, \&

\footnotetext{
${ }^{1}$ For instance, "Brazil" is a National squad, whereas "Brazil 1970" and "Brazil 1974" are, according to our definition, teams.
} 
Mondloch, 2009); which might be due to the larger body weight of successful professional hockey players (Deaner, Goetz, Shattuck, \& Schnotala, 2012).

Morphological and physiological traits are hard to alter, and therefore well suited to study so called honest signaling. Signals categorized as "honest" are objectively correlated with the characteristic the signal is implying, and are often involuntarily exhibited. In this paper we will focus on emotion display by players grouped in teams, and not on emotion display by players as individual entities. Since a team can be seen as more than a simple sum of its parts, emotion display by teams might in addition concern characteristics related to team selection, team cohesion, and team strategy.

Therefore, in teams, the value of "signals" might be influenced through decisions on multiple levels. Team managers select a set of players that will maximize the expected team performance given a tournament's stakes. Selected players might have, on average, higher levels of physical competitiveness with respect to the non-selected players. Even if subtle, such differences might be measurable through physiological and morphological traits. ${ }^{2}$ In addition, team managers might choose, among the selected players, to give more exposure to those that display dominance through certain traits; or induce players to communicate certain cues. The study of these strategic aspects, requires an easy to observe expression that can, to a certain degree, be altered by the individual.

Facial expressions are a prime candidate. While facial expressions are easy to modify by the individual, expressions are very reliably judged to be linked to certain traits (Oosterhof \& Todorov, 2008). For example, smiling individuals are consistently rated as more trustworthy (Centorrino, Djemai, Hopfensitz, Milinski, \& Seabright, 2015; van Leeuwen et al., 2017). However, interpretations by observers are not always correct, for example only genuine smiles could be linked to higher gains from exchange (Centorrino et al, 2015).

\footnotetext{
2 For instance, testosterone responses to competition are positively correlated to facial masculinity (Pound, Penton-Voak, \& Surridge, 2009); and the 2D:4D ratio of football players with international appearances is lower compared to professional players in the top four divisions of English football (Manning \& Taylor, 2001).
} 
The social function of emotions is to inform and prepare the individual to respond to certain stimuli, and emotional display allows groups to recognize others' feelings, beliefs and intentions (Keltner \& Haidt, 1999). For instance, seeing an angry face evokes a competitive interaction, whereas the same person with a happy face evokes a more cooperative interaction (Van Doorn, Heerdink, \& Van Kleef, 2012). Certain traits in emotion expressions indicate some underlying physiological reaction. To provide an example, the red anger face is linked to higher blood flow and thus a physical activation that might result in aggression; and sadness, typically associated with lethargy, is linked to objective sickness and physical disability (Stieglitz, Trumble, et al., 2015; Stieglitz, Schniter, von Rueden, Kaplan, \& Gurven, 2015). Other traits enhance cues in a strategic way. As an example, Sell, Cosmides, \& Tooby (2014) show that the muscle activations defining an angry face are also linked to judgments of greater strength.

While emotion expressions and reactions to them evolved in a time when expressions were observed in real time, this has changed in modern times. In modern conflicts, like political and sports contests, contestants can influence how others see them through selection of photos or videos, leaving more room for strategic signaling. Nowadays, sports contestants are continuously present through photographs, media campaigns on Twitter and Facebook, interviews and advertising. We might thus wonder whether athletes and teams use their media presence to display some desired characteristics. A team wishing to point out the strength and aggression related attributes of its players might try to select photos that are representative of such situations.

Emotion display in the face can be quantified and measured. We will use the commercial automated facial recognition software FaceReader 6 (Bijlstra \& Dotsch, 2011) and focus on ratings generated for two emotional expressions: anger and happiness. FaceReaders' classification of anger and happiness has been validated on the Radboud Face Database. Sensitivity (i.e., true positives rate) and specificity (i.e., true negatives rate) for anger reaches 86.4 and 98.8 percent, respectively. Sensitivity and specificity for happiness reaches 98.8 and 99.3 percent, respectively (calculations based on FaceReader 6.1 reference manual). ${ }^{3}$ Since this approach uses a neuronal network trained on previously

\footnotetext{
${ }^{3}$ FaceReader identifies a number of other emotion expressions (i.e. surprise, disgust, sadness and fear). However, accuracy for these, with the exception of surprise, is below $90 \%$.
} 
human rated expressions, it is linked to the Facial Action Coding System (FACS) developed by Ekman \& Rosenberg (1997). Ekman and co-authors documented how any displayed emotion can be defined through combinations of "action units," derived from the contraction of specific facial muscles.

To analyze facial expressions, we use a dataset of players' portraits from the collectible stickers that have been produced by "Panini" for every World Cup since 1970. This collection provides a unique dataset representing all involved teams and players and photographs should be taken as representative of a team's general photographic media presence. Soccer federations, and player themselves, are aware of the Panini sticker collection's worldwide fame and have been using the stickers to showcase their league. Collectible stickers in the UK were regarded as "something that was genuinely playing a part in showcasing the league and helping to publicise it" (Lansdowne, 2015). Multiple anecdotes exist of players that have used the stickers in their own communication with their fans and followers. ${ }^{4}$ For World Cup albums, each national soccer federation negotiates its license with Panini concerning the use of the official badges, jerseys and photographs. Since an essential element of the stickers are the photographs of players, teams can be strategic in how their players should be presented.

We will use the individual players' emotion display to characterize a team's overall emotion display. We will show that these scores are correlated with various measures of team performance in the World Cup, even after controlling for other important characteristics like the team's official FIFA ranking. There is consensus in the literature that this ranking, available since 1993, is the main predictor for forecasting World Cup outcomes (Dyte \& Clarke, 2000; Suzuki, Salasar, Leite, \& Louzada-Neto, 2010), ${ }^{5}$ even when controlling for competition specific covariates as bookmakers' odds (Groll, Schauberger, \& Tutz, 2015). The effect of emotions is small in comparison, but robust across multiple specifications. While our findings do not aim at improving World Cup forecasts, they provide novel and robust evidence of the role of emotion expressions in high stakes team contests, and its correlation with group performance.

\footnotetext{
${ }^{4}$ For example, in 2014 Mario Balotelli filled up the squad's pages in a Panini sticker album with images of himself and posted a photograph of the result on his official Facebook page.

${ }^{5}$ In fact, the simple rule of predicting that the two teams with the higher FIFA ranking will advance to the second stage outperformed experts and non-experts' predictions for the 2002 World Cup (Andersson, Edman, \& Ekman, 2005)
} 
The rest of the paper is structured as follows. In section 3.1. we explore the display of anger and happiness by the members of National squads and teams. In section 3.2. we then analyze the relationship between emotion display and World Cup performance. Multiple robustness checks will be presented in section 3.3. We will finally analyze behavior separately for offensive and defensive players in section 3.4. Section 4 will conclude.

\section{MethodS}

\subsection{Individual data of players attending the 1970-2014 World Cups}

We collected photo portraits of soccer players participating in 12 World Cups (from 1970 to 2014) as published by the collectible cards editor Panini. Panini has been editing series of collectible soccer player cards since 1961. In 1970 Panini began publishing the FIFA World Cup sticker album, cards became self-adhesive, and subsequently gained increasing attention. The market for collectibles cards in 2014 was such that Panini, according to its own reports, produced about 750 million individual stickers per week worldwide.

The FIFA World Cup albums that are jointly produced with the collectible cards have become more and more elaborate over the decades. For example, they include teams' emblems, the host's logo, mascot, and stadiums, in addition to photos of individual players. While in 1970 only 288 stickers were required to complete an album, the 2014 album required 639 stickers. The portraits of players form an elemental part of the collection, but the publisher's selection was less systematic in the early years. Specifically, in 1974, three out of sixteen teams were represented with only 6 players while others were represented with 11, 14, or 20 players. Since 1978 all teams are represented by 16 or 17 players.

We collected a total of 4,896 portraits from 76 different squads. Facial expressions in the photographs were automatically analyzed with the commercial facial analysis tool FaceReader 6 (Bijlstra \& Dotsch, 2011). FaceReader evaluates the activation level of six 
basic emotions: anger, happiness, disgust, fear, sadness, and surprise, which are nonexclusive. Specifically, each emotion is coded on a continuous scale from $0=$ no activation to $1=$ maximal activation. We focus in the following on the ratings generated for anger and happiness. FaceReader identifies the face and synthesizes an artificial face model based on the location of 500 key points and the facial texture between these points. It then classifies the facial expressions using an artificial neural network trained with 10,000 images (FaceReader 6, reference manual).

We also coded whether the photographs of a team were taken in a studio or in the stadium. Studio photographs are generally characterized by better picture quality, a uniform background and the player facing the camera (see Figure A1). Stadium portraits display players during game or during the opening ceremony and players usually do not face the camera. ${ }^{6}$

Picture quality was overall very high, and we were able to analyze $88 \%$ of the collected photographs (i.e., 4,318 portraits). The percentage of analyzed photographs per participating team falls below $50 \%$ for only 4 (out of 304 ) teams in our sample. For $56 \%$ of the participating teams there is at most one photograph that could not be analyzed.

Since FaceReader requires good lighting and a frontal view of the face, relatively more photographs are correctly identified for teams that had portraits taken in a studio. FaceReader was originally trained on Caucasian faces, but since version 6 , the software has had explicit improvements concerning Asian and African faces. Nevertheless, a smaller percentage of photographs per team were correctly analyzed for African and South American teams compared to European teams. Neither the fraction of participations nor the year of the World Cup were significant for predicting the number of photographs correctly analyzed (see Table A1 in the Appendix).

\subsection{Data on team performance and market value}

\footnotetext{
${ }^{6}$ Certain stadium photographs were edited (e.g. English teams that had due to copyright restrictions colors and symbols from the jersey removed). Faces were in these cases not edited and they were classified as stadium portraits.
} 
We gathered data from the Rec.Sport.Soccer Statistics Foundation (www.rsssf.com) for all matches that took place in the 12 editions of the World Cup held between 1970 and 2014. For each World Cup, we use three measures of team performance from the first stage (or group stage) plus an overall measure of team performance. First stage outcomes in our analysis are goal difference, number of goals scored, and number of goals conceded. ${ }^{7}$ We pay special attention to performance during the first stage for two reasons. First, the number of matches per team is the same for every competitor (three matches in total). Second, team quality during the first stage is more heterogeneous than in further stages of the tournament. The overall performance outcome is the FIFA's official World Cup ranking by tournament. ${ }^{8}$ The ranking is constructed using a lexicographic rule: the first criterion is the final stage reached by a given team, and the second criterion is the number of points obtained prior to elimination by this team. For example, the four teams eliminated in the quarter-finals are ranked $5^{\text {th }}$ to $8^{\text {th }}$, with their exact position depending on the points obtained in the tournament. ${ }^{9}$

We also coded the seeded teams for each World Cup and the team's official FIFA ranking, available since 1993, using FIFA's official documentation ${ }^{10}$ and coded the FIFA Confederation to which each team belonged. For the analyses reported in the next section, we pooled together the Asian and Oceanian Confederations. ${ }^{11}$

We also collected (using www.transfermarkt.com) information of the market value for every player in our database. Information on players' market value for years prior to 2009 are incomplete and were therefore not used. For the two last World Cups we record therefore two values: the market value of every player for the year previous to the World Cup (i.e. 2009 and 2013) and the value in the year of the World Cup (i.e. 2010

\footnotetext{
7 We excluded points as an outcome of analysis given the adoption of the 3 points rule in 1994 .

8 Obtained from FIFA's "Statistical Kit: Milestones and Superlatives": www.fifa.com/about-fifa/official-documents/matches-tournaments

9 Tie-breaking criteria are the goal difference and scored goals, in that order. For instance, in Brazil 2014, Colombia and Belgium won all their matches before both were eliminated in the quarter-finals. Colombia was ranked 5 th and Belgium was ranked 6 th because the goal difference was +8 for Colombia, and +3 for Belgium.

10 FIFA's document "Seedings 1930-2014" obtained from: www.fifa.com/about-fifa/official-documents/matches-tournaments Team's official FIFA ranking obtained from: http://www.fifa.com/fifa-world-ranking/associations/ 11 Pooling avoids ambiguities across years, since Australia moved from the Oceanian confederation (OFC) to the Asian confederation (AFC) in 2006.
} 
and 2014). To generate values for each team, we sum the individual market values of the players appearing in the corresponding (i.e. 2010 or 2014) Panini sticker album.

\section{RESULTS}

In the next section we will analyze the display of emotion expressions across teams and over time. In a second step we will link the display of emotion expressions to the observed outcomes from the twelve editions of the FIFA Soccer World Cup held between 1970 and 2014. Finally, we will show that the correlations between emotion portrayal and team performance are stronger among defensive compared to offensive players.

\subsection{Emotion display}

We detect a non-marginal activation in $84 \%$ of the photographs for anger and $73 \%$ of the photographs for happiness (i.e. activation $>0.0001$ ). The distribution of both emotions is highly skewed: for anger, the mean activation level is 0.1792 , whereas the median is 0.0086. For happiness, the mean activation level is 0.0986 and the median 0.0011 (see Figure 1 for the cumulative distributions). Though not exclusive by definition, we observe for anger and happiness a significant negative correlation at the player level $(\mathrm{N}=4,318$. Spearman $\rho=-0.187 ; \mathrm{p}<0.001)$.

\section{[FIGURE 1 GOES HERE]}

We find that $15 \%$ of the variation in the display of anger and $12 \%$ of the variation in the display of happiness can be attributed to the team. By contrast, no variation in the display of anger nor happiness can be attributed to the year. We obtain these intraclass correlations by running a mixed model with random intercepts, no covariates, and two nesting levels corresponding to the team and the year (see Table A2 in the Appendix). We obtain similar results defining the team as the single nesting level in separate regressions for each year. ${ }^{12}$

\footnotetext{
12 This model, equivalent to a random effects regression with no covariates, revealed that the variance in anger attributed to the team has remained relatively constant in each World Cup, with a mean level of $15 \%$, a minimum of $6 \%$ in 1978 , and a maximum of $22 \%$ in 2002 . Regarding the activation of happiness, the variance attributed to the team has been more volatile between years. In fact, the mean variance is $5 \%$
} 
Since our interest concerns the teams and not the individual players' performance, we aggregate individual emotion expressions at the team level. In the following we will use the mean activation per team per year. Alternative aggregation methods will be explored in the next section.

Our first observation concerns the distribution and correlation of anger and happiness on the team level. Panel A on Figure 2 shows the average activation of anger and happiness, averaged across all participations of the team. Teams are sorted, from top to bottom, according to increasing mean happiness. We observe a wide variance with respect to the average display of anger and happiness. Certain countries (like Yugoslavia, Hungary and Russia) show a very low display of happiness in combination with a high display of anger. Other countries (like USA, Denmark, Japan and Korea) display more happiness than anger. A comparison of the activation levels for anger and happiness, suggests a negative correlation between the display of the two emotions. Indeed, the correlation of the two emotions across all team level observations is statistically significant (i.e. $\mathrm{N}=304$ teams; Spearman $\rho=-0.303, \mathrm{p}<0.001$ ).

As we can observe from Panel B on Figure 2, emotion display is not constant over time. The mean display of anger is decreasing over time (Spearman correlation $\rho=-0.129$, $\mathrm{p}=0.024)$ while the mean display of happiness is increasing over time $(\rho=+0.109$, $\mathrm{p}=0.056$ ). The pattern is more pronounced for teams with at least five $\mathrm{e}^{13}$ participations between 1970 and 2014. For these teams the correlation becomes $\rho=-0.226(\mathrm{p}=0.002)$ for the mean display of anger, and $\rho=+0.181(\mathrm{p}=0.014)$ for the mean display of happiness.

\section{[FIGURE 2 GOES HERE]}

\subsection{Relationship between emotion display and behavior}

Having observed that display of emotions varies largely across teams and across time, we will next turn to respond whether emotion display can be linked to behavior by

between 1970 and 1986, with a minimum of 1\% in 1986; and 13\% between 1990 and 2014, with a maximum of $30 \%$ in 2010 (see Table A2 in the Appendix).

13 The median number of participations of our sample is five. 
teams. Recall that both display of anger and of happiness might be interpreted as an effort to communicate abilities that are beneficial for the team. However, the two emotions involve very different mechanisms.

We first present econometric evidence that indeed both emotions are linked to a team's performance. We run OLS regressions taking every participating team per year as unit of observation. That is, if a National squad took part in the last 12 editions of the World Cup, then we have 12 different observations, counted as teams, for that particular squad. We have a total of 304 observations: 16 teams per tournament between 1970 and 1978, 24 teams per tournament between 1982 and 1994, and 32 teams per tournament between 1998 and 2014.

The covariates of interest in our regressions are the team's mean activation levels of anger and happiness. Given the decreasing portrayal of anger and the increasing portrayal of happiness exhibited over time, we standardized the teams' display of anger and happiness with respect to the other participating teams in the same year. We will discuss in the next subsection, and show in an Appendix, that our results are robust to the use of the non-standardized mean activation levels of anger and happiness. They are also robust to an alternative aggregation method: the fraction of players per team whose activation exceeds a given threshold.

We include a number of variables as controls: to control for the strength of a team we include a confederation fixed effect, the fraction of World Cup participations of the squad $^{14}$, and a dummy variable indicating whether the team was seeded or not. ${ }^{15}$ To control for differences over time we include a year fixed effect. We further added a dummy indicating photographs taken in a studio.

Since our observations correspond to the aggregation of player-level data into group (or team) means we add analytic weights to our OLS regression. Specifically, we use the percentage of pictures per team successfully analyzed to weight observations. In this

\footnotetext{
14 This fraction is computed as the total number of participations, divided by the total number of participations in the qualifying stage (i.e., intentions to participate) since the foundation of the country's National Football Federation.

15 While many other measures of team quality exist, we focus on these as the most objective measures that are available for all teams over the studied time period from 1970 to 2014.
} 
way we correct for the fact that teams with fewer successfully analyzed players are subject to a greater variance at the time of aggregation.

Table 1 shows that display of anger as well as happiness is positively correlated with a favorable goal difference (i.e. more goals scored than conceded). This correlation is robust to the inclusion of our control variables ((1) and (2)). This confirms our hypothesis that the display of anger and happiness can be taken as a sign of higher team performance. ${ }^{16}$ We also observe the standardized display of anger and happiness is negatively correlated with the overall ranking in the World Cup ((7) and (8)). That is, teams that display either more anger or happiness, reach an overall better position in the whole tournament. Although the coefficient is larger for happiness than for anger these are not statistically different ( $F$ test from the regression in column 8 is 0.72 , $\mathrm{p}=0.398)$.

A higher goal difference might be achieved through two strategies: scoring goals (i.e. offensive play) or conceding less (i.e. defensive play). We therefore separately investigate the existing correlation between the display of emotions and goals scored, as well as goals conceded. We observe a clear difference with respect to the two emotions. While the display of happiness is linked to the scoring of goals ((3) and (4)), anger is linked to conceding fewer goals ((5) and (6)).17

\section{[TABLE 1 GOES HERE]}

The correlations of anger and happiness with team performance are robust to the introduction of National squad fixed effects (see Table A4). That is, the results reported in Table 1 hold even if we consider country's time-invariant characteristics that may

\footnotetext{
${ }^{16}$ None of the other emotions identified by the FaceReader (i.e., surprise, disgust, sadness and fear) show a systematic correlation with team performance. Table A3 in the Appendix reports the regression results when all six emotions are included as covariates. A marginal significant correlation can be observed under certain specifications for the emotion of disgust. However, this correlation becomes non-significant once controls are included because the display of disgust is correlated with a team being seeded for the group stage (Spearman $\rho: 0.218$, $\mathrm{p}$-value $<0.0001$ ). This correlation is in line with the hypothesis that disgust is associated to group superiority (Hodson et al., 2013). Coefficients indicating team's portrayal of surprise, disgust, sadness and fear remain statistically insignificant when portrayal of anger and happiness are excluded from the regression (results available upon request).

${ }^{17}$ Studio portraits accounted for approximately $15 \%$ of our observations with the first studio portraits appearing in 1994. The observed effects for goals scored and goals conceded also hold for the reduced sample of only stadium pictures.
} 
affect the display of anger and happiness (e.g. culture-specific concepts of emotional deviance that define culturally appropriate behavior). Table A4 also shows that results are similar, in terms of statistical significance, when using the standardized and the nonstandardized average activation levels of anger and happiness. The estimates with the non-standardized activation levels provides an additional interpretation for the results using fixed effects: changes over time in the portrayal of anger and happiness, for a given squad, are correlated with performance in a given World Cup.

\subsection{Robustness checks}

\subsubsection{Other aggregation procedures}

To confirm the robustness of results presented in the previous section we considered two alternative aggregation methods of displayed emotions on the team level. ${ }^{18}$ In the previous section we used standardized values with respect to the year. We therefore first replicate the previous analysis using the absolute value concerning the display of emotions (see Tables A5 to A8, column (1)). Second, we use as aggregation procedure the fraction of players per team (in a year) whose activation level exceeds a given threshold. We consider three different threshold levels (see columns 2-4 in Tables A5 to A8): $0.05,0.10$, and 0.20 . Recall that emotion display at the individual level was very highly skewed with a large percentage of players displaying no emotion. The selected threshold levels therefore represent in the case of anger that $36 \%, 30 \%$, and $24 \%$ of the 4,318 players in our sample are counted, respectively. In case of happiness the thresholds identify $19 \%, 16 \%$, and $13 \%$ of the players, respectively.

We qualitatively replicate the results with respect to goal difference (Table A5), goals scored (Table A6) and goals conceded (Table A7). We observe some differences with respect to overall World Cup ranking (Table A8). For all aggregation procedures we find a significant negative correlation between happiness and World Cup ranking, however the correlation between team's anger and World Cup ranking is negative but statistically non-significant using the threshold aggregation procedure.

\footnotetext{
18 We also investigated individual action units related to both emotions and detailed results are presented in Appendix B.
} 
In principle one might also consider the team's median activation level of anger and happiness as an additional aggregation procedure. Nevertheless, the data shows that activation levels for the median player of each team remain low for both emotions (e.g., the $75^{\text {th }}$ percentile of the distribution of the team's median anger and happiness is at a value of 0.066 and 0.005 , respectively). Therefore, the team's median level of anger and happiness is not very informative in a regression analysis. We should keep in mind though that the team's display of emotions is concentrated on less than half of the players. Aggregation procedures that give more weight to players portraying extreme levels of anger and happiness are therefore required to observe the correlation. In a later section we will further investigate which players in a team are crucial for the display of emotions (section 3.4).

\subsubsection{Team value}

We conduct an additional robustness check by including the teams' economic value as an additional proxy for the strength of a team. ${ }^{19}$ Wages of players are usually seen as a good estimator of their quality. For example, in the case of soccer clubs, expenditures in wages explain most of the variation in the club's final position in the league. For the English first and second divisions, this percentage of variation lies in between $59 \%$ and 89\% (Anderson \& Sally, 2013; Kuper \& Szymanski, 2009).

Although players selected to compete in a World Cup receive an economic compensation from their national soccer federation, this information is rarely made public. ${ }^{20}$ Instead we will approximate a teams' economic value by summing the players' individual valuations. Players' individual valuations have become public information in recent years and can be extracted from specialized databases. Since money appears to be able

\footnotetext{
${ }^{19}$ Similar results can be obtained when using the official FIFA ranking as covariate. We do not report these results here since the FIFA ranking is only available for the period since 1993, but are available upon request.

${ }^{20}$ Each team qualified to the World Cup receives from FIFA an amount that depends on the team's final position in the tournament (e.g., the 2014 World Cup winner, Germany, received 35 million dollars, whereas teams eliminated in the group stage received 2 million dollars each). However, the fraction of this amount that each national soccer federation decides to split among the national team's players is discretionary.
} 
to buy "talent," we expect that better national squads will have a roster with higher (economic) value.

We were able to construct the team's value for the World Cups held in 2010 and 2014 by collecting players' valuations from www.transfermarkt.com. For previous World Cups, players' information was incomplete. We compute the team's value by adding the individual value from every player appearing in the corresponding Panini sticker album. We also computed the team's value for the year before the corresponding World Cup.

Table 2 reports two regressions per outcome including a logarithmic transformation of the teams' value: with the value from the year preceding the World Cup (odd numbered regressions), and the value of the year of the World Cup (even numbered regressions). The team's value coefficients are significant at the $10 \%$ level for goal difference (see regressions (1) and (2)), and for goals scored (see regression (4)). The lack of a greater statistical significance (and any significance at all for other outcomes) for the team's value suggests that controlling for seeded teams, number of participations, and confederation fixed effects is already capturing "talent" heterogeneities among teams.

The significance of the correlation between the team's display of anger and happiness is robust to the introduction of the logarithm of the team's value to the regression analysis. This is remarkable keeping in mind that the number of observations dropped from 304 to 64 .

\section{[TABLE 2 GOES HERE]}

\subsection{Defensive/ Offensive players}

We have seen that a positive correlation between emotion display and team's performance in the World Cup exists. We further observed that this finding is driven by less than half of the players in a team. We now turn to the question if specific players (with respect to their role in the team) account for this. 
We will focus on two categories of players: players linked to offensive and players linked to defensive play. We use the fact that players in the Panini sticker collection are presented in the order of: goalkeepers, defenders, midfielders and attackers. ${ }^{21}$ We find a weak negative correlation between each player's position in the collection and anger activation level (Spearman $\rho=-0.031, \mathrm{p}=0.044$ ), and a weak positive correlation between each player's position and happiness activation level (Spearman $\rho=0.035, \mathrm{p}=0.023$ ). This correlation suggests an association between defensive roles and anger, and offensive roles and happiness.

We then define as defensive the first half of presented players (including goalkeepers, defenders and a few midfielders), and we define as offensive the second half of presented players (including most midfielders and attackers). We replicate the previous observed regressions with respect to anger and happiness, separately for defensive and offensive players (Table 3). We observe that the display of happiness is still predictive in each sub-group. By contrast, the display of anger remains predictive only for defensive players, and for one of the outcomes. Although coefficient sizes, regardless of their significance, are qualitatively larger for defensive players for both anger and happiness, the differences between regressions are not statistically significant (see Chi-squared tests reported in Table 3).

\section{[TABLE 3 GOES HERE]}

The division into defensive and offensive players might lead to misclassification problems due to midfielders. We therefore refine the above classification by dividing players into three groups; defining as defensive the players in the first tertile (including goalkeepers and defenders), and as offensive the players in the third tertile (including attackers and a few midfielders). Given this definition the statistical significance of the correlation between happiness and team's performance increases for defensive players, while we observe a drop in statistical significance for offensive players (see Table A9).

\footnotetext{
${ }^{21}$ A second goalkeeper is the last sticker from each team in some editions of the Panini sticker album. It includes every team in the 1978, 1986, 1994 albums, and Brazil, France, Germany, Italy, Russia, Scotland, and Spain in the 1982 album, among others. We recoded the second goalkeeper with the same number assigned to the first goalkeeper.
} 
The relationship between anger and goal difference retains its significance for defensive players, whereas no significant correlation is found for offensive players.

Therefore, the relative level of emotions displayed by defensive players (compared to other defensive players that participated in the same World Cup), has more weight in the team's signaling of performance with respect to the emotions displayed by offensive players. A team with defensive players that display more anger (with respect to defensive players from other teams) will show better defensive performance, while a team with defensive players that display more happiness (with respect to defensive players from other teams) will show better offensive performance.

The lack of a significant correlation between emotion portrayal and team's performance for offensive players could be due to little variation across teams in the display of anger and happiness for these players. We therefore verified whether similar conclusions can be drawn with respect to the absolute levels of emotion display. Specifically, we ran additional regressions with the non-standardized average activation levels of anger and happiness, including squad fixed effects (see Table A10 in the Appendix). We find that non-standardized anger and happiness, when fixed-effects are included, are correlated with performance for defensive players. ${ }^{22}$

We therefore conclude that defensive players' expressions seem to weight more than those from offensive players, both with respect to the difference in their emotion display compared to other defensive players in the same World Cup (Table 3), as to the difference in display compared to defensive players from the same squad that participated in another World Cup (Table A10). For offensive players we see that the reference group matters: we observe a correlation of performance with happiness compared to other offensive players in the same World Cup; and a correlation of performance with anger compared to players from the same squad in other years.

\footnotetext{
${ }^{22}$ Coefficients, in this case, should be interpreted as showing a correlation between a squad's performance in a particular World Cup, and the deviation of the emotion level by the squad's players in that year from the average emotion portrayal of the squad in all other participations.
} 


\section{Discussion And Conclusions}

We analyzed the portrayed emotions in 4,318 soccer players photographs, from 304 teams over the twelve most recent editions of the FIFA Soccer World Cup, and found a positive correlation between team performance in the World Cup's group stage and the portray of anger and happiness.

Which emotion is displayed in a photograph, can depend on many variables. It might be due to (1) characteristics of the person (i.e. emotional traits), (2) it might be due to the emotions experienced at the moment of the photograph or it might be (3) which photograph was selected to be displayed by either the player, the photographer or others. Due to these multiple mechanisms our results should not be interpreted as "teams whose players are angrier or happier perform better" but rather as "teams whose players look angrier or happier perform better". We conjecture that teams are interested in displaying anger and happiness in the photographs because both emotions are associated to high levels of dominance (Knutson, 1996).

Our results reveal different mechanisms for the correlation between anger and happiness with goal difference in the first stage of the World Cup. The correlation with anger is (mostly) driven by conceding fewer goals, whereas the correlation with happiness is driven by scoring more goals. The literature describing the functional nature of emotions gives us some clues for interpretation (Knutson, 1996; Keltner and Haidt, 1999). Anger evokes low group affiliation, competitiveness, and the definition of in-group boundaries. Hence, the anger face evokes hostility toward the out-group. By contrast, happiness evokes high group affiliation and confidence. We therefore show that, for the case of soccer, the display of angry expressions is linked to a focus on defense. That is, preventing others from scoring or a "sabotage activity" to reduce the opponent's output (del Corral, Prieto-Rodríguez, \& Simmons, 2010; Garicano \& PalaciosHuerta, 2006). ${ }^{23}$ By contrast, the display of happiness is linked to offensive play or an increase in the team's own output (i.e., scoring).

\footnotetext{
${ }^{23}$ In other team sports that rely more on aggression for scoring (e.g. rugby), anger might be however related to offensive behavior.
} 
The portrayal of anger and happiness appears to have opposite patterns over time. While the display of anger was particularly popular in the first half of our period of study (1970-1986), the display of happiness became particularly salient in the second half of our period of study (1990-2014). Incidentally, the increased display of happiness coincides with the adoption of the " 3 points for a win" rule from 1994. The aim of introducing this rule to the FIFA World Cup was to encourage more attacking and scoring (Garicano \& Palacios-Huerta, 2006). We further observed that the time trend in emotion displays was driven by teams with at least five participations between 1970 and 2014. That fact that experienced teams, those with an above-median number of World Cup participations, show these trends, suggests that some strategic aspects in how photographs are made or selected drive these results.

Interestingly though the correlation between happiness display and scoring goals is mainly driven by happiness displayed by defensive players (when compared to other defensive players participating in the same World Cup). It is therefore important to keep in mind that the relationship between emotion display and performance is observed on the team and not at the individual level. Notably, less than half of the players of a team account for the observed display of emotions. Given the team nature of soccer we believe that the analysis on the team level is the most appropriate. We therefore did not discuss potentially interesting questions concerning individual performance or even individual contributions to team outcomes. It further remains an open question whether similar mechanisms exist also for other non-team sports.

Another important point is that we only analyzed photographs of male soccer players. Notably the very first Panini World Cup soccer album for women was produced only in 2011. Due to the links between testosterone, aggressiveness and anger and differing norms concerning smiling and display of happiness for men and women, we might expect different results for female players.

\section{ACKNOWLEDGEMENTS}

We would like to acknowledge financial support from the ANR project SINT ANR-15CE33-0005-01 as well as support through the Institute of Advanced Study in Toulouse 
(IAST). We are indebted to Paula Zamora for excellent research assistance. We thank Jonathan Stieglitz and Boris van Leeuwen for their useful comments. 


\section{REFERENCES}

Anderson, C., \& Sally, D. (2013). The numbers game : why everything you know about soccer is wrong.

Andersson, P., Edman, J., \& Ekman, M. (2005). Predicting the World Cup 2002 in soccer: Performance and confidence of experts and non-experts. International Journal of Forecasting, 21(3), 565-576. https://doi.org/10.1016/J.IJFORECAST.2005.03.004

Attrill, M. J., Gresty, K. A., Hill, R. A., \& Barton, R. A. (2008). Red shirt colour is associated with long-term team success in English football. Journal of Sports Sciences, 26(6), 577-582. https://doi.org/10.1080/02640410701736244

Bijlstra, G., \& Dotsch, R. (2011). FaceReader 4 emotion classification performance on images from the Radboud Faces Database. Mimeo, (1). Retrieved from http://www.gijsbijlstra.nl

Carré, J. M., \& McCormick, C. M. (2008). In your face: facial metrics predict aggressive behaviour in the laboratory and in varsity and professional hockey players. Proceedings. Biological Sciences, 275(1651), 2651-6. https://doi.org/10.1098/rspb.2008.0873

Carré, J. M., McCormick, C. M., \& Mondloch, C. J. (2009). Facial Structure Is a Reliable Cue of Aggressive Behavior. Psychological Science, 20(10), 1194-1198. https://doi.org/10.1111/j.1467-9280.2009.02423.x

Centorrino, S., Djemai, E., Hopfensitz, A., Milinski, M., \& Seabright, P. (2015). Honest signaling in trust interactions: smiles rated as genuine induce trust and signal higher earning opportunities. Evolution and Human Behavior, 36(1), 8-16. https://doi.org/10.1016/J.EVOLHUMBEHAV.2014.08.001

Deaner, R. O., Goetz, S. M. M., Shattuck, K., \& Schnotala, T. (2012). Body weight, not facial width-to-height ratio, predicts aggression in pro hockey players. Journal of Research in Personality, 46(2), 235-238. https://doi.org/10.1016/J.JRP.2012.01.005

del Corral, J., Prieto-Rodríguez, J., \& Simmons, R. (2010). The Effect of Incentives on Sabotage: The Case of Spanish Football. Journal of Sports Economics, 11(3), 243260. https://doi.org/10.1177/1527002509340666

Dyte, D., \& Clarke, S. R. (2000). A ratings based Poisson model for World Cup soccer simulation. Journal of the Operational Research Society, 51(8), 993-998. https://doi.org/10.1057/palgrave.jors.2600997

Ekman, P., \& Rosenberg, E. L. (1997). What the face reveals : basic and applied studies of spontaneous expression using the facial action coding system (FACS). Oxford University Press.

Fortunato, L., \& Clauset, A. (2016). Revisiting the effect of red on competition in humans. bioRxiv. Cold Spring Harbor Laboratory. https://doi.org/10.1101/086710

Garicano, L., \& Palacios-Huerta, I. (2006). Sabotage in tournaments: Making the beautiful game a bit less beautiful. Discussion Paper, 26. https://doi.org/10.1016/S10432760(97)84344-5

Groll, A., Schauberger, G., \& Tutz, G. (2015). Prediction of major international soccer tournaments based on team-specific regularized Poisson regression: An application to the FIFA World Cup 2014. Journal of Quantitative Analysis in Sports, 11(2), 97115. https://doi.org/10.1515/jqas-2014-0051

Hanin, Y. (2000). Emotions in Sport. Human Kinetics.

Hill, R. A., \& Barton, R. A. (2005). Psychology: Red enhances human performance in contests. Nature, 435(7040), 293-293. https://doi.org/10.1038/435293a

Hodson, G., Choma, B. L., Boisvert, J., Hafer, C. L., MacInnis, C. C., \& Costello, K. (2013). 
The role of intergroup disgust in predicting negative outgroup evaluations. Journal of Experimental Social Psychology, 49(2), 195-205.

https://doi.org/10.1016/J.JESP.2012.11.002

Ioan, S., Sandulache, M., Avramescu, S., Ilie, A., Neacsu, A., Zagrean, L., \& Moldovan, M. (2007). Red is a distractor for men in competition. Evolution and Human Behavior, 28(4), 285-293. https://doi.org/10.1016/J.EVOLHUMBEHAV.2007.03.001

Jackson, S. J., \& Hokowhitu, B. (2002). Sport, Tribes, and Technology. Journal of Sport and Social Issues, 26(2), 125-139. https://doi.org/10.1177/0193723502262002

Keltner, D., \& Haidt, J. (1999). Social Functions of Emotions at Four Levels of Analysis. Cognition \& Emotion, 13(5), 505-521. https://doi.org/10.1080/026999399379168

Knutson, B. (1996). Facial expressions of emotion influence interpersonal trait inferences. Journal of Nonverbal Behavior, 20(3), 165-182. https://doi.org/10.1007/BF02281954

Krenn, B. (2014). The impact of uniform color on judging tackles in association football. Psychology of Sport and Exercise, 15(2), 222-225.

https://doi.org/10.1016/J.PSYCHSPORT.2013.11.007

Kuper, S., \& Szymanski, S. (2009). Soccernomics: Why England Loses, Why Spain, Germany, and Brazil Win, and Why the U.S., Japan, AustraliaÑand Even Iraq are Destined to Become the Kings of the World's Most Popular Sport. Retrieved from https://books.google.com/books?id=ijVnAgAAQBAJ\&pgis=1

Lansdowne, G. (2015). Stuck on you.

Manning, J. T., \& Taylor, R. P. (2001). Second to fourth digit ratio and male ability in sport: implications for sexual selection in humans. Evolution and Human Behavior: Official Journal of the Human Behavior and Evolution Society, 22(1), 61-69. https://doi.org/10.1016/S1090-5138(00)00063-5

Matsumoto, D., \& Willingham, B. (2006). The thrill of victory and the agony of defeat: Spontaneous expressions of medal winners of the 2004 Athens Olympic games. Journal of Personality and Social Psychology, 91(3), 568-581. https://doi.org/10.1037/0022-3514.91.3.568

Mazur, A., \& Booth, A. (1998). Testosterone and dominance in men. The Behavioral and Brain Sciences, 21(3), 353-63-97. Retrieved from http://www.ncbi.nlm.nih.gov/pubmed/10097017

Oosterhof, N. N., \& Todorov, A. (2008). The functional basis of face evaluation. Proceedings of the National Academy of Sciences of the United States of America, 105(32), 11087-92. https://doi.org/10.1073/pnas.0805664105

Pound, N., Penton-Voak, I. S., \& Surridge, A. K. (2009). Testosterone responses to competition in men are related to facial masculinity. Proceedings. Biological Sciences, 276(1654), 153-9. https://doi.org/10.1098/rspb.2008.0990

Sell, A., Cosmides, L., \& Tooby, J. (2014). The human anger face evolved to enhance cues of strength. Evolution and Human Behavior, 35(5), 425-429. https://doi.org/10.1016/J.EVOLHUMBEHAV.2014.05.008

Stieglitz, J., Schniter, E., von Rueden, C., Kaplan, H., \& Gurven, M. (2015). Functional Disability and Social Conflict Increase Risk of Depression in Older Adulthood Among Bolivian Forager-Farmers. The Journals of Gerontology Series B: Psychological Sciences and Social Sciences, 70(6), 948-956. https://doi.org/10.1093/geronb/gbu080

Stieglitz, J., Trumble, B. C., Thompson, M. E., Blackwell, A. D., Kaplan, H., \& Gurven, M. (2015). Depression as sickness behavior? A test of the host defense hypothesis in a high pathogen population. Brain, Behavior, and Immunity, 49, 130-139. 
https://doi.org/10.1016/j.bbi.2015.05.008

Suzuki, A. K., Salasar, L. E. B., Leite, J. G., \& Louzada-Neto, F. (2010). A Bayesian approach for predicting match outcomes: The 2006 (Association) Football World Cup. Journal of the Operational Research Society, 61(10), 1530-1539. https://doi.org/10.1057/jors.2009.127

Van Doorn, E. A., Heerdink, M. W., \& Van Kleef, G. A. (2012). Emotion and the construal of social situations: Inferences of cooperation versus competition from expressions of anger, happiness, and disappointment. Cognition \& Emotion, 26(3), 442-461. https://doi.org/10.1080/02699931.2011.648174

van Leeuwen, B., Noussair, C. N., Offerman, T., Suetens, S., van Veelen, M., \& van de Ven, J. (2017). Predictably Angry-Facial Cues Provide a Credible Signal of Destructive Behavior. Management Science, mnsc.2017.2727. https://doi.org/10.1287/mnsc.2017.2727

Wiggins, J. S., Trapnell, P., \& Phillips, N. (1988). Psychometric and Geometric Characteristics of the Revised Interpersonal Adjective Scales (IAS-R). Multivariate Behavioral Research, 23(4), 517-530. https://doi.org/10.1207/s15327906mbr2304_8

Wood, R. I., \& Stanton, S. J. (2012). Testosterone and sport: current perspectives. Hormones and Behavior, 61(1), 147-55. https://doi.org/10.1016/j.yhbeh.2011.09.010 


\section{Figures AND TABLES}

Figure 1. Cumulative distribution of anger and happiness activations at the individual and team level.
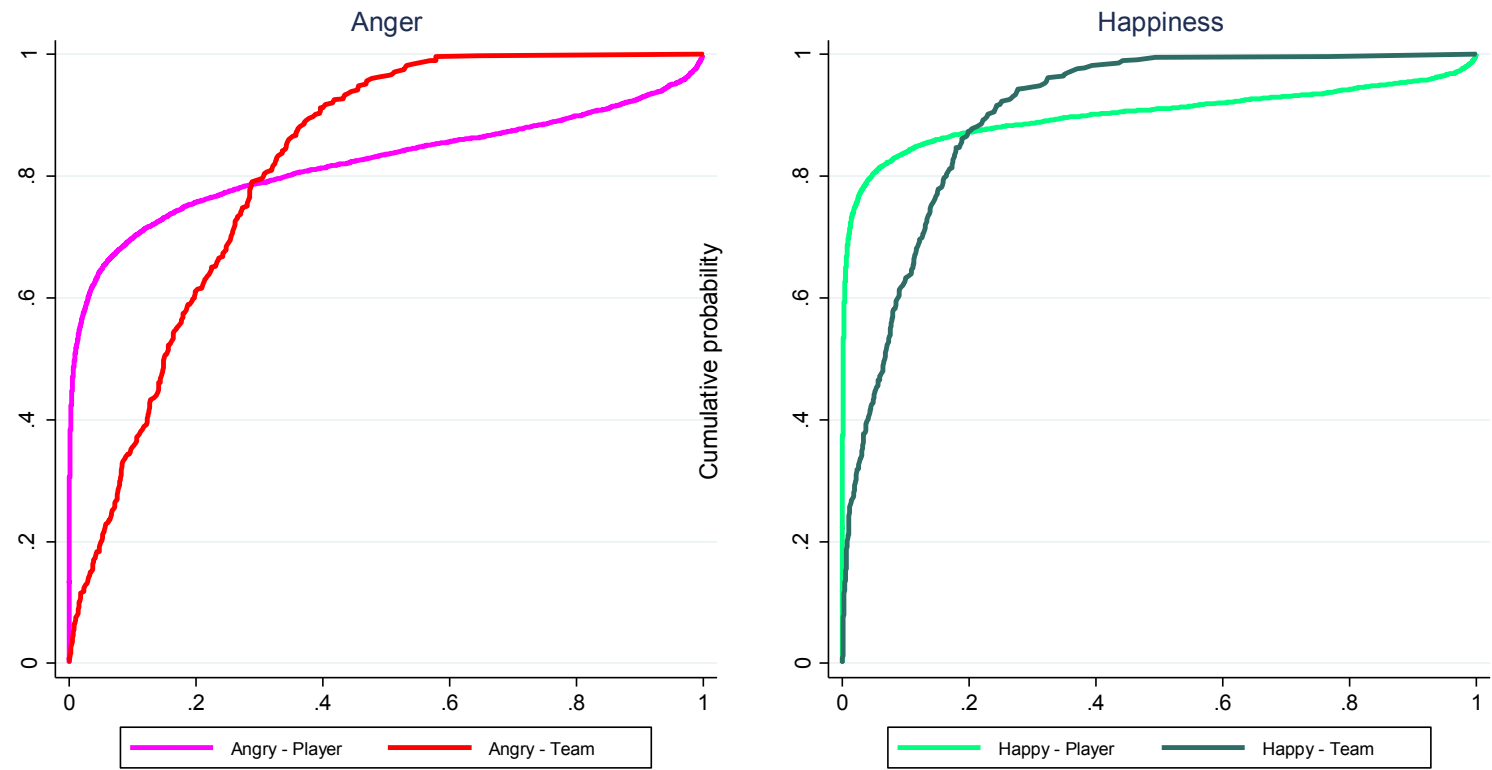
Figure 2. Mean activation of anger and happiness at team level. Panel (A) displays mean activation by team over all years (sorted by happiness). Panel (B) displays distributions per World-Cup year over all teams.

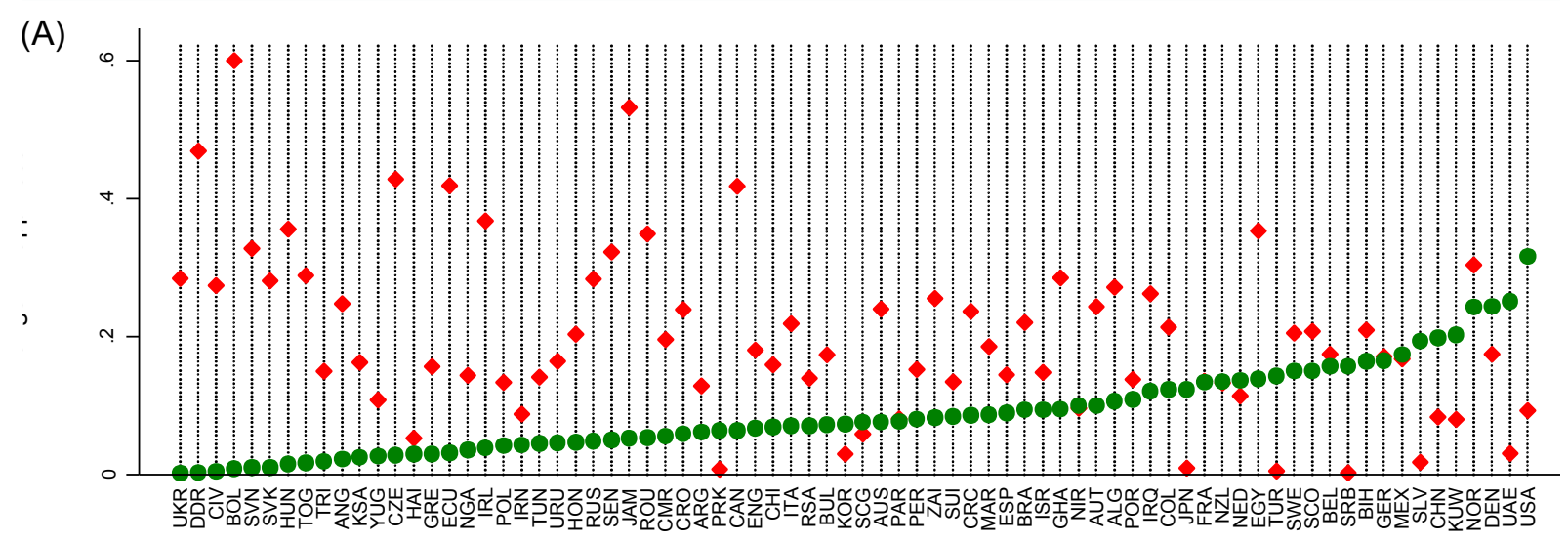

(B)

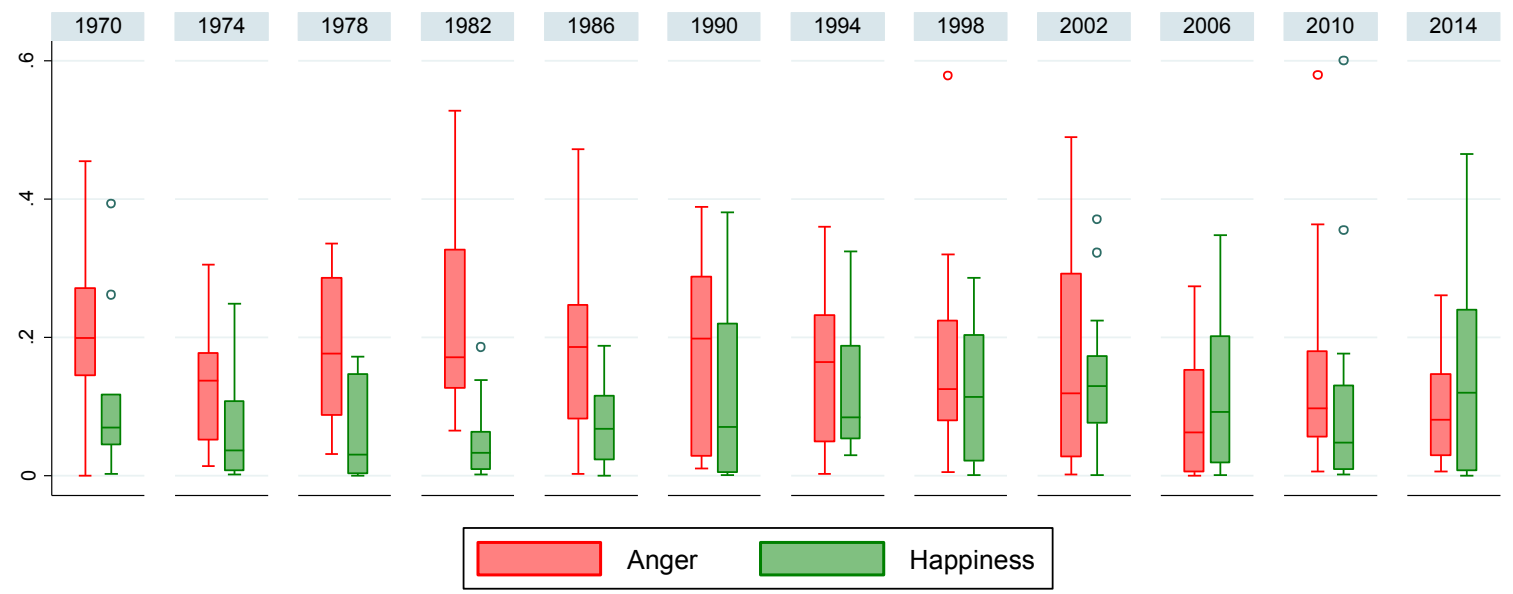


Table 1. Team performance and standardized emotion display. OLS coefficients reported for goal difference, goals scored and goals conceded in the group (first) stage, and for ranking in the World Cup.

\begin{tabular}{|c|c|c|c|c|c|c|c|c|}
\hline \multirow{3}{*}{$\begin{array}{l}\text { VARIABLES } \\
\text { Angry (std) }\end{array}$} & \multirow{2}{*}{\multicolumn{2}{|c|}{$\begin{array}{l}\text { (1) }(2) \\
\text { Goal difference } \\
\text { Stage } 1\end{array}$}} & (3) & (4) & (5) & (6) & (7) & (8) \\
\hline & & & \multicolumn{2}{|c|}{$\begin{array}{l}\text { Goals scored } \\
\text { Stage } 1\end{array}$} & \multicolumn{2}{|c|}{$\begin{array}{c}\text { Goals conceded } \\
\text { Stage } 1\end{array}$} & \multicolumn{2}{|c|}{ World Cup Ranking } \\
\hline & $1.344 * *$ & $0.947 * *$ & 0.482 & 0.353 & $-0.863 * *$ & $-0.594^{*}$ & $-1.937^{*}$ & -1.234 \\
\hline & $(0.532)$ & $(0.468)$ & $(0.304)$ & $(0.298)$ & $(0.356)$ & $(0.333)$ & (1.112) & $(0.918)$ \\
\hline \multirow[t]{2}{*}{ Happy (std) } & $1.170 * *$ & $1.546 * * *$ & $0.795 * *$ & $0.989 * * *$ & -0.375 & -0.557 & $-2.713^{* *}$ & $-3.080 * * *$ \\
\hline & $(0.583)$ & $(0.533)$ & $(0.316)$ & $(0.339)$ & $(0.390)$ & $(0.379)$ & $(1.140)$ & $(1.045)$ \\
\hline \multirow[t]{2}{*}{ Constant } & -0.0110 & -0.0799 & $3.783^{* * *}$ & $3.581 * *$ & $3.794 * * *$ & $3.661 * * *$ & $13.99 * * *$ & $9.984 * * *$ \\
\hline & $(0.228)$ & $(0.863)$ & $(0.134)$ & $(0.549)$ & $(0.152)$ & $(0.613)$ & $(0.490)$ & $(1.690)$ \\
\hline Controls & No & Yes & No & Yes & No & Yes & No & Yes \\
\hline Observations & 304 & 304 & 304 & 304 & 304 & 304 & 304 & 304 \\
\hline R-squared & 0.026 & 0.357 & 0.020 & 0.237 & 0.019 & 0.269 & 0.019 & 0.452 \\
\hline
\end{tabular}

Table 2. Total player value of teams in year preceding World Cup and in year of World Cup. OLS coefficients reported for goal difference, goals scored and goals conceded in the group (first) stage, and for ranking in the World Cup.

\begin{tabular}{|c|c|c|c|c|c|c|c|c|}
\hline \multirow{2}{*}{$\begin{array}{l}\text { VARIABLES } \\
\text { Angry (std) }\end{array}$} & \multicolumn{2}{|c|}{$\begin{array}{c}\text { Goal difference } \\
\text { Stage } 1\end{array}$} & \multicolumn{2}{|c|}{$\begin{array}{c}\text { Goals scored } \\
\text { Stage } 1 \\
\end{array}$} & \multicolumn{2}{|c|}{$\begin{array}{c}\text { Goals conceded } \\
\text { Stage } 1\end{array}$} & \multicolumn{2}{|c|}{ World Cup Ranking } \\
\hline & $\begin{array}{l}2.318^{* *} \\
(1.058)\end{array}$ & $\begin{array}{c}2.554^{* *} \\
(1.066)\end{array}$ & $\begin{array}{l}1.195^{*} \\
(0.647)\end{array}$ & $\begin{array}{c}1.303 * * \\
(0.646)\end{array}$ & $\begin{array}{l}-1.123 \\
(0.761)\end{array}$ & $\begin{array}{l}-1.250 \\
(0.776)\end{array}$ & $\begin{array}{c}-5.163^{*} \\
(2.778)\end{array}$ & $\begin{array}{c}-5.614^{* *} \\
(2.775)\end{array}$ \\
\hline Happy (std) & $\begin{array}{l}2.161^{* *} \\
(0.910)\end{array}$ & $\begin{array}{c}2.117 * * \\
(0.907)\end{array}$ & $\begin{array}{c}1.645^{* * * *} \\
(0.556)\end{array}$ & $\begin{array}{c}1.642^{* * *} \\
(0.550)\end{array}$ & $\begin{array}{l}-0.516 \\
(0.655)\end{array}$ & $\begin{array}{l}-0.476 \\
(0.661)\end{array}$ & $\begin{array}{c}-5.524^{* *} \\
(2.390)\end{array}$ & $\begin{array}{c}-5.516^{* *} \\
(2.362)\end{array}$ \\
\hline $\begin{array}{l}\text { Log(Team value } \\
\text { previous year) }\end{array}$ & $\begin{array}{c}1.502^{* * *} \\
(0.535)\end{array}$ & & $\begin{array}{c}0.505 \\
(0.327)\end{array}$ & & $\begin{array}{c}-0.996 * * \\
(0.385)\end{array}$ & & $\begin{array}{l}-2.023 \\
(1.405)\end{array}$ & \\
\hline $\begin{array}{l}\text { Log(Team value } \\
\text { World Cup's year) }\end{array}$ & & $\begin{array}{c}1.735^{* * *} \\
(0.612)\end{array}$ & & $\begin{array}{l}0.693^{*} \\
(0.371)\end{array}$ & & $\begin{array}{c}-1.042^{* *} \\
(0.446)\end{array}$ & & $\begin{array}{l}-2.841^{*} \\
(1.594)\end{array}$ \\
\hline Constant & $\begin{array}{c}-27.22^{* * *} \\
(9.487)\end{array}$ & $\begin{array}{c}-31.88^{* * *} \\
(11.04)\end{array}$ & $\begin{array}{l}-6.331 \\
(5.803)\end{array}$ & $\begin{array}{l}-9.863 \\
(6.692)\end{array}$ & $\begin{array}{c}20.88^{* * *} \\
(6.829)\end{array}$ & $\begin{array}{c}22.02^{* * *} \\
(8.039)\end{array}$ & $\begin{array}{c}54.15^{* *} \\
(24.92)\end{array}$ & $\begin{array}{c}69.47^{* *} \\
(28.73)\end{array}$ \\
\hline Observations & 64 & 64 & 64 & 64 & 64 & 64 & 64 & 64 \\
\hline R-squared & 0.491 & 0.492 & 0.449 & 0.460 & 0.412 & 0.399 & 0.494 & 0.504 \\
\hline
\end{tabular}

Controls included: fraction of participations in World Cup per team, whether team pictures were taken in a studio, whether the team was seeded, confederation and World Cup fixed effects. Standard errors in parentheses. ${ }^{* * *} p<0.01,{ }^{* *} p<0.05,{ }^{*} p<0.1$. 
Table 3. Defensive versus offensive players with standardized emotion measures. OLS coefficients reported for goal difference, goals scored and goals conceded in the group (first) stage, and for ranking in the World Cup. Standardized emotion measures with respect to other defensive and offensive players. Standardization in columns (1) to (4) was computed with respect to other defensive players in the same year. The standardization in columns (5) to (8) was computed with respect to other offensive players in the same year. P-value for Chi-squared tests for equality of coefficient between the regressions for defensive and offensive players reported in italics and squared brackets.

\begin{tabular}{|c|c|c|c|c|c|c|c|c|}
\hline \multirow{3}{*}{ VARIABLES } & (1) & $(2)$ & (3) & (4) & (5) & (6) & (7) & (8) \\
\hline & \multicolumn{4}{|c|}{ Defensive players } & \multicolumn{4}{|c|}{ Offensive players } \\
\hline & $\begin{array}{c}\text { Goal } \\
\text { difference }\end{array}$ & $\begin{array}{c}\text { Goals } \\
\text { scored }\end{array}$ & $\begin{array}{c}\text { Goals } \\
\text { conceded }\end{array}$ & Ranking & $\begin{array}{c}\text { Goal } \\
\text { difference }\end{array}$ & $\begin{array}{c}\text { Goals } \\
\text { scored }\end{array}$ & $\begin{array}{c}\text { Goals } \\
\text { conceded }\end{array}$ & Ranking \\
\hline \multirow[t]{2}{*}{ Angry (std) } & $0.779 * *$ & 0.287 & $-0.492 *$ & -1.162 & 0.537 & 0.164 & -0.373 & -0.588 \\
\hline & $(0.390)$ & $(0.247)$ & $(0.277)$ & $(0.766)$ & $(0.429)$ & $(0.272)$ & $(0.303)$ & $(0.836)$ \\
\hline$p\left(\chi^{2}\right)$ Defensive $=$ Offensive & [0.668] & {$[0.730]$} & {$[0.761]$} & {$[0.602]$} & & & & \\
\hline \multirow[t]{2}{*}{ Happy (std) } & $1.176^{* * *}$ & $0.844 * * *$ & -0.332 & $-2.048 * *$ & $0.934 * *$ & $0.550 *$ & -0.383 & $-2.221 * *$ \\
\hline & $(0.439)$ & $(0.279)$ & $(0.312)$ & $(0.863)$ & $(0.466)$ & $(0.296)$ & $(0.329)$ & (0.909) \\
\hline$p\left(\chi^{2}\right)$ Defensive $=$ Offensive & {$[0.706]$} & [0.411] & [0.917] & [0.882] & & & & \\
\hline Observations & 304 & 304 & 304 & 304 & 304 & 304 & 304 & 304 \\
\hline R-squared & 0.356 & 0.239 & 0.268 & 0.448 & 0.345 & 0.223 & 0.264 & 0.446 \\
\hline
\end{tabular}

Controls included: fraction of participations in World Cup per team, whether team pictures were taken in a studio, whether the team was seeded, confederation and World Cup fixed effects. Standard errors in parentheses. ${ }^{* * *} p<0.01,{ }^{* *} p<0.05,{ }^{*} p<0.1$ 


\section{Appendix A: Additional Figures and Tables}

Figure A1. Example of player portraits from Panini sticker albums. Extract from 2014 Panini album displaying defensive players from Germany (top) and Argentina (bottom).

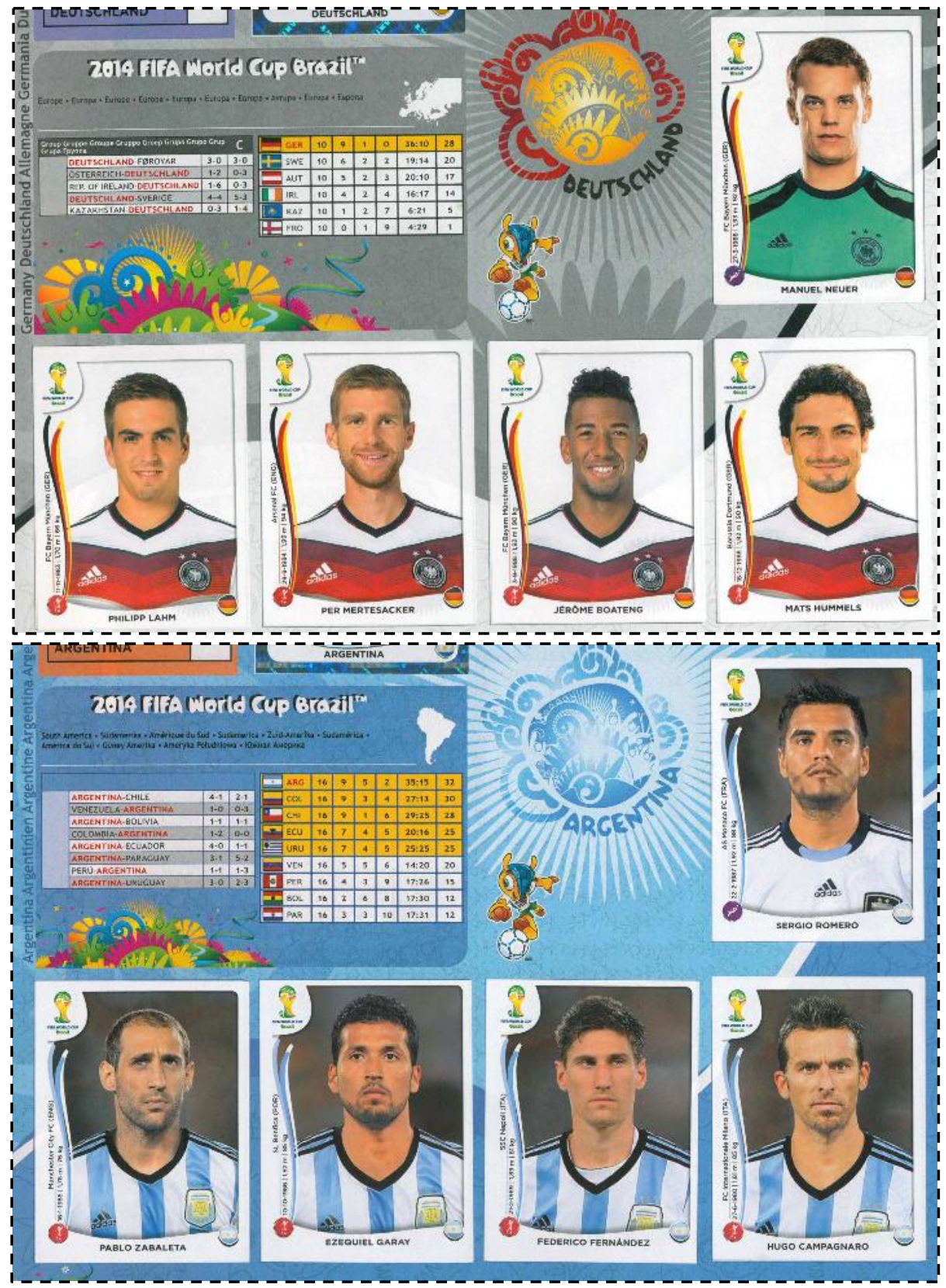


Table A1. Correlations concerning the percentage of photographs (per team) sucessfully analyzed by FaceReader.

\begin{tabular}{|c|c|c|c|}
\hline \multirow{2}{*}{$\begin{array}{l}\text { VARIABLES } \\
\text { Year }\end{array}$} & \multicolumn{3}{|c|}{$\begin{array}{c}\% \text { of photographs analyzed } \\
\text { per team }\end{array}$} \\
\hline & 0.0005 & & $(0.0006)$ \\
\hline Studio dummy (=0 if picture taken in stadium) & 0.0419 & $*$ & $(0.0218)$ \\
\hline Fraction of participations & 0.0566 & & $(0.0475)$ \\
\hline Asia dummy (AFC) & 0.0218 & & $(0.0238)$ \\
\hline Africa dummy (CAF) & -0.104 & $* * *$ & $(0.0226)$ \\
\hline \multicolumn{4}{|l|}{ Central and North America dummy } \\
\hline (CONCACAF) & -0.0004 & & $(0.0250)$ \\
\hline South America dummy (CONMEBOL) & -0.0421 & $* *$ & $(0.0196)$ \\
\hline Constant & -0.286 & & $(1.253)$ \\
\hline Observations & \multicolumn{3}{|c|}{304} \\
\hline R-squared & \multicolumn{3}{|c|}{0.128} \\
\hline
\end{tabular}

Table A2. Intraclass correlation (ICC). Results obtained using a mixed model with two nesting levels corresponding to team and year. We also validated a non-zero ICC at the team level for each World Cup.

\begin{tabular}{|c|c|c|c|c|c|c|c|c|c|c|c|c|c|c|}
\hline & \multicolumn{2}{|c|}{ Two nesting levels } & \multicolumn{12}{|c|}{ One nesting level - ICC team } \\
\hline & ICC team & ICC year & 1970 & 1974 & 1978 & 1982 & 1986 & 1990 & 1994 & 1998 & 2002 & 2006 & 2010 & 2014 \\
\hline nger & 0.15 & 0.00 & 0.15 & 0.18 & 0.06 & 0.20 & 0.12 & 0.13 & 0.17 & 0.17 & 0.22 & 0.13 & 0.14 & 0.12 \\
\hline appines & 0.12 & 0.00 & 0.12 & 0.03 & 0.04 & 0.07 & 0.01 & 0.11 & 0.06 & 0.11 & 0.09 & 0.12 & 0.30 & 0.14 \\
\hline
\end{tabular}


Table A3. Replication of Table 1 including standardized activation levels for all six emotions computed by FaceReader. OLS coefficients reported for goal difference, goals scored and goals conceded in the group (first) stage, and for ranking in the World Cup.

\begin{tabular}{|c|c|c|c|c|c|c|c|c|}
\hline \multirow[b]{2}{*}{ VARIABLES } & (1) & (2) & (3) & (4) & (5) & (6) & (7) & (8) \\
\hline & \multicolumn{2}{|c|}{$\begin{array}{c}\text { Goal difference } \\
\text { Stage } 1\end{array}$} & \multicolumn{2}{|c|}{$\begin{array}{l}\text { Goals scored } \\
\text { Stage } 1\end{array}$} & \multicolumn{2}{|c|}{$\begin{array}{c}\text { Goals conceded } \\
\text { Stage } 1\end{array}$} & \multicolumn{2}{|c|}{ World Cup Ranking } \\
\hline Angry (std) & $\begin{array}{l}1.298^{* *} \\
(0.551)\end{array}$ & $\begin{array}{c}0.970 * * \\
(0.483)\end{array}$ & $\begin{array}{l}0.514^{*} \\
(0.308)\end{array}$ & $\begin{array}{c}0.423 \\
(0.308)\end{array}$ & $\begin{array}{c}-0.784^{* *} \\
(0.368)\end{array}$ & $\begin{array}{l}-0.547 \\
(0.342)\end{array}$ & $\begin{array}{l}-1.557 \\
(1.161)\end{array}$ & $\begin{array}{l}-1.046 \\
(0.949)\end{array}$ \\
\hline Happy (std) & $\begin{array}{c}0.938 \\
(0.623)\end{array}$ & $\begin{array}{c}1.809 * * * \\
(0.560)\end{array}$ & $\begin{array}{c}0.690 * * \\
(0.345)\end{array}$ & $\begin{array}{c}1.111^{* * *} \\
(0.357)\end{array}$ & $\begin{array}{l}-0.248 \\
(0.416)\end{array}$ & $\begin{array}{c}-0.697 * \\
(0.397)\end{array}$ & $\begin{array}{l}-1.788 \\
(1.169)\end{array}$ & $\begin{array}{c}-3.259 * * * \\
(1.101)\end{array}$ \\
\hline Surprised (std) & $\begin{array}{l}0.0943 \\
(0.757)\end{array}$ & $\begin{array}{c}0.425 \\
(0.644)\end{array}$ & $\begin{array}{l}-0.0967 \\
(0.505)\end{array}$ & $\begin{array}{c}-0.00940 \\
(0.410)\end{array}$ & $\begin{array}{l}-0.191 \\
(0.505)\end{array}$ & $\begin{array}{l}-0.435 \\
(0.456)\end{array}$ & $\begin{array}{c}1.051 \\
(1.543)\end{array}$ & $\begin{array}{c}0.255 \\
(1.266)\end{array}$ \\
\hline Disgusted (std) & $\begin{array}{c}0.965 \\
(0.697)\end{array}$ & $\begin{array}{l}-0.459 \\
(0.598)\end{array}$ & $\begin{array}{c}0.165 \\
(0.371)\end{array}$ & $\begin{array}{l}-0.494 \\
(0.381)\end{array}$ & $\begin{array}{c}-0.800 * \\
(0.465)\end{array}$ & $\begin{array}{r}-0.0355 \\
(0.424)\end{array}$ & $\begin{array}{c}-2.448^{*} \\
(1.354)\end{array}$ & $\begin{array}{c}0.406 \\
(1.176)\end{array}$ \\
\hline Sad (std) & $\begin{array}{l}-0.115 \\
(0.679)\end{array}$ & $\begin{array}{c}0.535 \\
(0.580)\end{array}$ & $\begin{array}{l}-0.407 \\
(0.429)\end{array}$ & $\begin{array}{l}-0.209 \\
(0.369)\end{array}$ & $\begin{array}{l}-0.291 \\
(0.453)\end{array}$ & $\begin{array}{c}-0.744^{*} \\
(0.411)\end{array}$ & $\begin{array}{l}-0.545 \\
(1.231)\end{array}$ & $\begin{array}{l}-1.436 \\
(1.140)\end{array}$ \\
\hline Scared (std) & $\begin{array}{r}-0.0585 \\
(0.808)\end{array}$ & $\begin{array}{c}0.739 \\
(0.692)\end{array}$ & $\begin{array}{l}-0.0406 \\
(0.398)\end{array}$ & $\begin{array}{c}0.357 \\
(0.441)\end{array}$ & $\begin{array}{l}0.0179 \\
(0.539)\end{array}$ & $\begin{array}{l}-0.382 \\
(0.490)\end{array}$ & $\begin{array}{c}1.838 \\
(1.365)\end{array}$ & $\begin{array}{l}-0.291 \\
(1.361)\end{array}$ \\
\hline Constant & $\begin{array}{c}-0.00894 \\
(0.228)\end{array}$ & $\begin{array}{l}-0.117 \\
(0.864)\end{array}$ & $\begin{array}{c}3.785^{* * *} \\
(0.135)\end{array}$ & $\begin{array}{c}3.560 * * * \\
(0.550)\end{array}$ & $\begin{array}{c}3.794 * * * \\
(0.152)\end{array}$ & $\begin{array}{c}3.677^{* * *} \\
(0.612)\end{array}$ & $\begin{array}{c}13.99 * * * \\
(0.489)\end{array}$ & $\begin{array}{c}9.997 * * * \\
(1.697)\end{array}$ \\
\hline Controls & No & Yes & No & Yes & No & Yes & No & Yes \\
\hline Observations & 304 & 304 & 304 & 304 & 304 & 304 & 304 & 304 \\
\hline R-squared & 0.033 & 0.366 & 0.025 & 0.244 & 0.030 & 0.283 & 0.037 & 0.456 \\
\hline
\end{tabular}

Controls included: fraction of participations in World Cup per team, whether team pictures were taken in a studio, whether the team was seeded, confederation and World Cup fixed effects. Standard errors in parentheses.

*** $p<0.01, * * p<0.05, * p<0.1$

Table A4. Replication of Table 1: Introduction of National squad fixed effects. OLS coefficients reported for goal difference, goals scored and goals conceded in the group (first) stage, and for ranking in the World Cup. In columns (1) to (4) team average levels of anger and happiness are standardized with respect to other participating teams in the same World Cup. In columns (5) to (8) team average levels are not standardized.

\begin{tabular}{|c|c|c|c|c|c|c|c|c|}
\hline \multirow{3}{*}{ VARIABLES } & (1) & (2) & (3) & (4) & (5) & (6) & (7) & (8) \\
\hline & \multicolumn{4}{|c|}{ Standardized emotion activation level } & \multicolumn{4}{|c|}{ Non-standardized emotion activation level } \\
\hline & $\begin{array}{c}\text { Goal } \\
\text { difference }\end{array}$ & $\begin{array}{l}\text { Goals } \\
\text { scored }\end{array}$ & $\begin{array}{c}\text { Goals } \\
\text { conceded }\end{array}$ & Ranking & $\begin{array}{c}\text { Goal } \\
\text { difference }\end{array}$ & $\begin{array}{l}\text { Goals } \\
\text { scored }\end{array}$ & $\begin{array}{c}\text { Goals } \\
\text { conceded }\end{array}$ & Ranking \\
\hline Angry & $\begin{array}{c}1.600 * * * \\
(0.527)\end{array}$ & $\begin{array}{c}0.805 * * \\
(0.375)\end{array}$ & $\begin{array}{c}-0.794 * * \\
(0.367)\end{array}$ & $\begin{array}{c}-2.675^{* *} \\
(1.152)\end{array}$ & $\begin{array}{c}5.296 * * * \\
(1.694)\end{array}$ & $\begin{array}{c}2.666 * * \\
(1.205)\end{array}$ & $\begin{array}{c}-2.630 * * \\
(1.180)\end{array}$ & $\begin{array}{c}-8.752^{* *} \\
(3.708)\end{array}$ \\
\hline Happy & $\begin{array}{c}1.295^{* *} \\
(0.561)\end{array}$ & $\begin{array}{c}0.898 * * \\
(0.399)\end{array}$ & $\begin{array}{l}-0.397 \\
(0.390)\end{array}$ & $\begin{array}{c}-2.673 * * \\
(1.227)\end{array}$ & $\begin{array}{c}5.721 * * \\
(2.238)\end{array}$ & $\begin{array}{c}3.861 * * \\
(1.592)\end{array}$ & $\begin{array}{l}-1.860 \\
(1.559)\end{array}$ & $\begin{array}{c}-11.26 * * \\
(4.899)\end{array}$ \\
\hline Controls & Yes & Yes & Yes & Yes & Yes & Yes & Yes & Yes \\
\hline Observations & 304 & 304 & 304 & 304 & 304 & 304 & 304 & 304 \\
\hline R-squared & 0.620 & 0.436 & 0.586 & 0.597 & 0.622 & 0.438 & 0.587 & 0.597 \\
\hline
\end{tabular}

Controls included: fraction of participations in World Cup per team, whether team pictures were taken in a studio, whether the team was seeded, squad and World Cup fixed effects. Standard errors in parentheses. ${ }^{* * *} \mathrm{p}<0.01,{ }^{* *}$ $p<0.05, * p<0.1$ 
Table A5. Robustness check for goal difference in Stage 1. Emotion aggregation based on nonstandardized mean and threshold levels.

\begin{tabular}{|c|c|c|c|c|}
\hline \multirow{3}{*}{$\begin{array}{l}\text { Dependent variable: } \\
\text { Goal difference - Stage } 1\end{array}$} & \multirow{3}{*}{$\begin{array}{c}\text { (1) } \\
\text { Non-standardized } \\
\text { Mean }\end{array}$} & (2) & (3) & (4) \\
\hline & & \multicolumn{3}{|c|}{ \# of Players Above an Activation Level } \\
\hline & & Threshold > 0.05 & Threshold > 0.10 & Threshold $>0.20$ \\
\hline \multirow[t]{2}{*}{ Angry } & $3.272 * *$ & $1.779 *$ & 1.271 & 1.639 \\
\hline & $(1.508)$ & $(0.970)$ & $(1.003)$ & $(1.077)$ \\
\hline \multirow[t]{2}{*}{ Happy } & $6.591 * * *$ & $2.952 * *$ & $3.608 * * *$ & $3.690 * *$ \\
\hline & $(2.123)$ & $(1.329)$ & $(1.379)$ & $(1.447)$ \\
\hline \multirow[t]{2}{*}{ Constant } & -1.387 & -1.613 & -1.398 & -1.351 \\
\hline & $(0.955)$ & (1.019) & $(0.995)$ & $(0.964)$ \\
\hline Observations & 304 & 304 & 304 & 304 \\
\hline R-squared & 0.361 & 0.353 & 0.354 & 0.357 \\
\hline
\end{tabular}

Controls included: fraction of participations in World Cup per team, whether team pictures were taken in a studio, whether the team was seeded, confederation and World Cup fixed effects. Standard errors in parentheses. ${ }^{* * *} p<0.01$,

$* * p<0.05, * p<0.1$

Table A6. Robustness check for goal scored in Stage 1. Emotion aggregation based on nonstandardized mean and threshold levels.

\begin{tabular}{|c|c|c|c|c|}
\hline \multirow{3}{*}{$\begin{array}{l}\text { Dependent variable: } \\
\text { Goals scored - Stage } 1\end{array}$} & \multirow{3}{*}{$\begin{array}{c}\text { (1) } \\
\text { Non-standardized } \\
\text { Mean }\end{array}$} & (2) & (3) & (4) \\
\hline & & \multicolumn{3}{|c|}{ \# of Players Above an Activation Level } \\
\hline & & Threshold >0.05 & Threshold > 0.10 & Threshold $>0.20$ \\
\hline \multirow[t]{2}{*}{ Angry } & 1.234 & 0.901 & 0.582 & 0.466 \\
\hline & $(0.959)$ & $(0.611)$ & $(0.634)$ & $(0.683)$ \\
\hline \multirow[t]{2}{*}{ Happy } & $4.200 * * *$ & $2.624 * * *$ & $2.689 * * *$ & $2.681 * *$ \\
\hline & $(1.350)$ & $(0.838)$ & $(0.872)$ & $(0.918)$ \\
\hline \multirow[t]{2}{*}{ Constant } & $2.936 * * *$ & $2.541 * * *$ & $2.752 * * *$ & $2.924 * * *$ \\
\hline & $(0.607)$ & $(0.642)$ & $(0.629)$ & $(0.612)$ \\
\hline Observations & 304 & 304 & 304 & 304 \\
\hline R-squared & 0.240 & 0.245 & 0.242 & 0.240 \\
\hline
\end{tabular}

Controls included: fraction of participations in World Cup per team, whether team pictures were taken in a studio, whether the team was seeded, confederation and World Cup fixed effects. Standard errors in parentheses. $* * * p<0.01$, $* * p<0.05, * p<0.1$ 
Table A7. Robustness check for goal conceded in Stage 1. Emotion aggregation based on nonstandardized mean and threshold levels.

\begin{tabular}{|c|c|c|c|c|}
\hline \multirow{3}{*}{$\begin{array}{l}\text { Dependent variable: } \\
\text { Goals conceded - Stage } 1\end{array}$} & \multirow{3}{*}{$\begin{array}{c}\text { (1) } \\
\text { Non-standardized } \\
\text { Mean }\end{array}$} & (2) & (3) & (4) \\
\hline & & \multicolumn{3}{|c|}{ \# of Players Above an Activation Level } \\
\hline & & Threshold $>0.05$ & Threshold $>0.10$ & Threshold $>0.20$ \\
\hline \multirow[t]{2}{*}{ Angry } & $-2.038 *$ & -0.878 & -0.689 & -1.173 \\
\hline & $(1.073)$ & $(0.690)$ & $(0.714)$ & $(0.765)$ \\
\hline \multirow[t]{2}{*}{ Happy } & -2.391 & -0.328 & -0.920 & -1.009 \\
\hline & $(1.510)$ & $(0.945)$ & $(0.981)$ & $(1.028)$ \\
\hline \multirow[t]{2}{*}{ Constant } & $4.323 * * *$ & $4.154 * * *$ & $4.150 * * *$ & $4.275^{* * *}$ \\
\hline & $(0.679)$ & $(0.725)$ & $(0.708)$ & $(0.685)$ \\
\hline Observations & 304 & 304 & 304 & 304 \\
\hline R-squared & 0.271 & 0.263 & 0.263 & 0.268 \\
\hline
\end{tabular}

Controls included: fraction of participations in World Cup per team, whether team pictures were taken in a studio, whether the team was seeded, confederation and World Cup fixed effects. Standard errors in parentheses. ${ }^{* * *} p<0.01$, ** $p<0.05, * p<0.1$

Table A8. Robustness check for World Cup ranking. Emotion aggregation based on non-standardized mean and threshold levels.

\begin{tabular}{|c|c|c|c|c|}
\hline \multirow{3}{*}{$\begin{array}{l}\text { Dependent variable: } \\
\text { World Cup ranking }\end{array}$} & \multirow{3}{*}{$\begin{array}{c}(1) \\
\text { Non-standardized } \\
\text { Mean }\end{array}$} & (2) & (3) & (4) \\
\hline & & \multicolumn{3}{|c|}{ \# of Players Above an Activation Level } \\
\hline & & Threshold $>0.05$ & Threshold $>0.10$ & Threshold $>0.20$ \\
\hline \multirow[t]{2}{*}{ Angry } & -4.144 & -0.0232 & 0.251 & -0.275 \\
\hline & (2.959) & $(1.912)$ & $(1.974)$ & $(2.121)$ \\
\hline \multirow[t]{2}{*}{ Happy } & $-12.73 * * *$ & $-4.727^{*}$ & $-6.032 * *$ & $-6.707 * *$ \\
\hline & $(4.164)$ & $(2.621)$ & $(2.715)$ & $(2.850)$ \\
\hline \multirow[t]{2}{*}{ Constant } & $12.03 * * *$ & $11.18^{* * *}$ & $11.22 * * *$ & $11.32 * * *$ \\
\hline & $(1.873)$ & $(2.010)$ & $(1.959)$ & $(1.900)$ \\
\hline Observations & 304 & 304 & 304 & 304 \\
\hline R-squared & 0.453 & 0.441 & 0.444 & 0.446 \\
\hline
\end{tabular}

Controls included: fraction of participations in World Cup per team, whether team pictures were taken in a studio, whether the team was seeded, confederation and World Cup fixed effects. Standard errors in parentheses. ${ }^{* * *} p<0.01,{ }^{* *} p<0.05$, * $p<0.1$ 
Table A9. Replication of Table 3: excluding midfield players. Defensive players are defined as the first tertile, while offensive players are defined as the last tertile. P-value for Chi-squared tests for equality of coefficient between the regressions for defensive and offensive players reported in italics and squared brackets.

\begin{tabular}{|c|c|c|c|c|c|c|c|c|}
\hline \multirow{3}{*}{ VARIABLES } & (1) & (2) & (3) & (4) & (5) & (6) & (7) & (8) \\
\hline & \multicolumn{4}{|c|}{ Defensive players } & \multicolumn{4}{|c|}{ Offensive players } \\
\hline & $\begin{array}{c}\text { Goal } \\
\text { difference }\end{array}$ & $\begin{array}{c}\text { Goals } \\
\text { scored }\end{array}$ & $\begin{array}{c}\text { Goals } \\
\text { conceded }\end{array}$ & Ranking & $\begin{array}{c}\text { Goal } \\
\text { difference }\end{array}$ & $\begin{array}{l}\text { Goals } \\
\text { scored }\end{array}$ & $\begin{array}{c}\text { Goals } \\
\text { conceded }\end{array}$ & Ranking \\
\hline Angry (std) & $\begin{array}{c}0.680 * * * \\
(0.342)\end{array}$ & $\begin{array}{c}0.326 \\
(0.225)\end{array}$ & $\begin{array}{l}-0.353 \\
(0.240)\end{array}$ & $\begin{array}{l}-0.576 \\
(0.704)\end{array}$ & $\begin{array}{c}0.467 \\
(0.367)\end{array}$ & $\begin{array}{c}0.101 \\
(0.234)\end{array}$ & $\begin{array}{l}-0.366 \\
(0.258)\end{array}$ & $\begin{array}{l}-0.0161 \\
(0.718)\end{array}$ \\
\hline$p\left(\chi^{2}\right)$ Defensive $=$ Offensive & [0.665] & [0.499] & [0.970] & {$[0.555]$} & & & & \\
\hline Happy (std) & $\begin{array}{c}1.224^{* * *} \\
(0.367)\end{array}$ & $\begin{array}{c}0.877^{* * *} \\
(0.241)\end{array}$ & $\begin{array}{l}-0.346 \\
(0.257)\end{array}$ & $\begin{array}{c}-2.276^{* * *} \\
(0.754)\end{array}$ & $\begin{array}{l}0.650^{*} \\
(0.388)\end{array}$ & $\begin{array}{c}0.227 \\
(0.247)\end{array}$ & $\begin{array}{l}-0.423 \\
(0.273)\end{array}$ & $\begin{array}{c}-1.277^{*} \\
(0760)\end{array}$ \\
\hline$p\left(\chi^{2}\right)$ Defensive $=$ Offensive & [0.276] & [0.037] & [0.849] & {$[0.297]$} & & & & \\
\hline Observations & 301 & 301 & 301 & 301 & 304 & 304 & 304 & 304 \\
\hline R-squared & 0.364 & 0.245 & 0.274 & 0.453 & 0.343 & 0.216 & 0.268 & 0.440 \\
\hline
\end{tabular}

Controls included: fraction of participations in World Cup per team, whether team pictures were taken in a studio, whether the team was seeded, confederation and World Cup fixed effects. Standard errors in parentheses. ${ }^{* * *} p<0.01,{ }^{* *} p<0.05,{ }^{*} p<0.1$

Table A10. Defensive versus offensive players with non-standardized emotion measures and squad fixed effects. OLS coefficients reported for goal difference, goals scored and goals conceded in the group (first) stage, and for ranking in the World Cup. P-value for Chi-squared tests for equality of coefficient between the regressions for defensive and offensive players reported in italics and squared brackets.

\begin{tabular}{|c|c|c|c|c|c|c|c|c|}
\hline \multirow{3}{*}{ VARIABLES } & (1) & (2) & (3) & (4) & (5) & $(6)$ & (7) & (8) \\
\hline & \multicolumn{4}{|c|}{ Defensive players } & \multicolumn{4}{|c|}{ Offensive players } \\
\hline & $\begin{array}{c}\text { Goal } \\
\text { difference }\end{array}$ & $\begin{array}{l}\text { Goals } \\
\text { scored }\end{array}$ & $\begin{array}{c}\text { Goals } \\
\text { conceded }\end{array}$ & Ranking & $\begin{array}{c}\text { Goal } \\
\text { difference }\end{array}$ & $\begin{array}{c}\text { Goals } \\
\text { scored }\end{array}$ & $\begin{array}{c}\text { Goals } \\
\text { conceded }\end{array}$ & Ranking \\
\hline Angry & $\begin{array}{c}4.098 * * * \\
(1.364)\end{array}$ & $\begin{array}{c}1.948 * * \\
(0.987)\end{array}$ & $\begin{array}{c}-2.150 * * \\
(0.954)\end{array}$ & $\begin{array}{c}-6.735^{* *} \\
(3.021)\end{array}$ & $\begin{array}{c}3.324^{* *} \\
(1.466)\end{array}$ & $\begin{array}{c}1.681 \\
(1.057)\end{array}$ & $\begin{array}{l}-1.644 \\
(1.013)\end{array}$ & $\begin{array}{l}-6.120^{*} \\
(3.195)\end{array}$ \\
\hline$p\left(\chi^{2}\right)$ Defensive $=$ Offensive & [0.646] & {$[0.827]$} & {$[0.662]$} & {$[0.867]$} & & & & \\
\hline Happy & $\begin{array}{c}4.838^{* * *} \\
(1.859)\end{array}$ & $\begin{array}{c}3.606 * * * \\
(1.346)\end{array}$ & $\begin{array}{l}-1.232 \\
(1.300)\end{array}$ & $\begin{array}{l}-7.164^{*} \\
(4.119)\end{array}$ & $\begin{array}{c}2.760 \\
(1.901)\end{array}$ & $\begin{array}{c}1.791 \\
(1.371)\end{array}$ & $\begin{array}{l}-0.969 \\
(1.314)\end{array}$ & $\begin{array}{c}-8.537^{* *} \\
(4.144)\end{array}$ \\
\hline$p\left(\chi^{2}\right)$ Defensive $=$ Offensive & [0.309] & {$[0.242]$} & [0.861] & {$[0.788]$} & & & & \\
\hline Observations & 304 & 304 & 304 & 304 & 304 & 304 & 304 & 304 \\
\hline R-squared & 0.642 & 0.449 & 0.606 & 0.610 & 0.629 & 0.433 & 0.600 & 0.608 \\
\hline
\end{tabular}

Controls included: fraction of participations in World Cup per team, whether team pictures were taken in a studio, whether the team was seeded, squad and World Cup fixed effects. Standard errors in parentheses. ${ }^{* * *} p<0.01, * * p<0.05,{ }^{*} p<0.1$ 


\section{APPENDIX B}

\section{Alternative Emotion Measures: Action units}

So far we have employed measures of anger and happiness reported by the commercial software FaceReader 6. FaceReader is based on an artificial neural network, which was trained on over 10,000 manually annotated images. Manual annotation was based on the set of action units activated described in the Facial Action Coding System (FACS). In addition to the aggregate emotion output, FaceReader also provides information on the specific action units that were activated. We can therefore use the detailed information on action units to investigate whether any specific action unit is responsible for the overall effect. We focus on six action units related to the activation of anger and happiness. AU4 (brow lowerer: Depressor Glabellae, Depressor Supercilli, and Currugator muscles), AU5 (upper lid raiser: Levator palpebrae superioris muscle), AU7 (lid tightener: Orbicularis oculi, and pars palpebralis muscles) and AU23 (lip tightener: Orbicularis oris muscle) are associated to the activation of anger. AU6 (cheek raiser: Orbicularis oculi, and pars orbitalis muscles), and AU12 (lip corner puller: Zygomatic major muscle) are associated to the activation of happiness.

We test how action units are correlated with anger and happiness in our sample of soccer player photographs. Columns (1) and (2) in Table B1 confirm that, at the player level, AU4, AU7 and AU23 are positively correlated with anger and columns (5) and (6) show that AU6 and AU12 are positively correlated with happiness. However, for both anger and happiness, the explanatory power of our linear model remains relatively low (Anger: $\mathrm{R}^{2}<0.169$; Happiness: $\mathrm{R}^{2}<0.379$ ). Consequently, for anger, the significance of the effects decreases when activations are aggregated at the team level (columns (3) and (4)). With the binary classification for each action unit, this aggregation is interpreted as the fraction of players for whom a specific action unit was active. With the continuous measure of activation, the aggregation of an action unit is interpreted as the team's mean activation level.

Meanwhile both AU6 and AU12 retain also under aggregation high significance levels (columns (7) and (8)). This implies that we cannot account for the previous observed 
effects of anger and happiness by use of actions units (Table B2). The only two action units that are statistically significant in Table B2 reflect the negative correlation between the display of anger and happiness. AU05, associated to anger, is negatively correlated with goals scored, an outcome for which we consistently found a positive relationship with happiness. By contrast, AU06, associated to happiness, is positively correlated with goals conceded, an outcome for which we consistently found a negative relationship with anger. 
Table B1. Individual action units and emotion measure by Facereader. OLS coefficients reported at the player and team levels, with a binary and a continuous definition for the activation of each action unit.

\begin{tabular}{|c|c|c|c|c|c|c|c|c|}
\hline \multirow{4}{*}{ VARIABLES } & (1) & (2) & (3) & (4) & (5) & (6) & (7) & (8) \\
\hline & \multicolumn{4}{|c|}{ Anger } & \multicolumn{4}{|c|}{ Happiness } \\
\hline & \multicolumn{2}{|c|}{ Players } & \multicolumn{2}{|c|}{ Teams } & \multicolumn{2}{|c|}{ Players } & \multicolumn{2}{|c|}{ Teams } \\
\hline & Binary AU & Continuous AU & Binary AU & Continuous AU & Binary AU & Continuous AU & Binary AU & Continuous AU \\
\hline 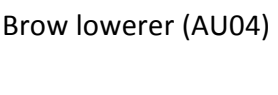 & $\begin{array}{c}0.154 * * * \\
(0.009)\end{array}$ & $\begin{array}{c}0.0437^{* * *} \\
(0.002)\end{array}$ & $\begin{array}{c}1.062^{* * *} \\
(0.118)\end{array}$ & $\begin{array}{c}0.252 * * * \\
(0.031)\end{array}$ & $\begin{array}{c}-0.05 * * * \\
(0.007)\end{array}$ & $\begin{array}{c}-0.014^{* * *} \\
(0.002)\end{array}$ & $\begin{array}{c}-0.26 * * * \\
(0.094)\end{array}$ & $\begin{array}{c}-0.0600 * * \\
(0.025)\end{array}$ \\
\hline $\begin{array}{l}\text { Upper lid raiser } \\
\text { (AU05) }\end{array}$ & $\begin{array}{l}-0.0187 \\
(0.025)\end{array}$ & $\begin{array}{l}-0.0005 \\
(0.008)\end{array}$ & $\begin{array}{l}-0.0162 \\
(0.352)\end{array}$ & $\begin{array}{l}0.0100 \\
(0.116)\end{array}$ & $\begin{array}{c}0.0181 \\
(0.0174)\end{array}$ & $\begin{array}{c}0.00574 \\
(0.00558)\end{array}$ & $\begin{array}{c}0.222 \\
(0.282)\end{array}$ & $\begin{array}{c}0.0689 \\
(0.0963)\end{array}$ \\
\hline 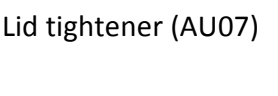 & $\begin{array}{c}0.114^{* * *} \\
(0.011)\end{array}$ & $\begin{array}{c}0.0444 * * * \\
(0.0036)\end{array}$ & $\begin{array}{l}0.279 * \\
(0.147)\end{array}$ & $\begin{array}{c}0.0991 * * \\
(0.0453)\end{array}$ & $\begin{array}{c}0.0114 \\
(0.0073)\end{array}$ & $\begin{array}{l}-0.00129 \\
(0.0025)\end{array}$ & $\begin{array}{l}-0.0832 \\
(0.118)\end{array}$ & $\begin{array}{l}-0.0515 \\
(0.0376)\end{array}$ \\
\hline Lip tightener (AU23) & $\begin{array}{c}0.067^{* * *} \\
(0.018)\end{array}$ & $\begin{array}{c}0.0247^{* * *} \\
(0.0056)\end{array}$ & $\begin{array}{c}0.469 \\
(0.296)\end{array}$ & $\begin{array}{l}0.225^{* *} \\
(0.0904)\end{array}$ & $\begin{array}{l}-0.030 * * \\
(0.0125)\end{array}$ & $\begin{array}{c}-0.00865 * * \\
(0.00385)\end{array}$ & $\begin{array}{l}-0.143 \\
(0.237)\end{array}$ & $\begin{array}{c}-0.106 \\
(0.0750)\end{array}$ \\
\hline Cheek raiser (AU06) & $\begin{array}{l}-0.04 * * * \\
(0.0109)\end{array}$ & $\begin{array}{c}-0.0175^{* * *} \\
(0.0029)\end{array}$ & $\begin{array}{l}-0.201 \\
(0.149)\end{array}$ & $\begin{array}{c}-0.0918^{* *} \\
(0.0360)\end{array}$ & $\begin{array}{l}0.134 * * * \\
(0.00759)\end{array}$ & $\begin{array}{c}0.0436 * * * \\
(0.00199)\end{array}$ & $\begin{array}{c}0.485^{* * *} \\
(0.119)\end{array}$ & $\begin{array}{c}0.147^{* * *} \\
(0.0299)\end{array}$ \\
\hline $\begin{array}{l}\text { Lip corner puller } \\
\text { (AU12) }\end{array}$ & $\begin{array}{c}-0.06 * * * \\
(0.014)\end{array}$ & $\begin{array}{c}-0.0170 * * * \\
(0.0042)\end{array}$ & $\begin{array}{l}-0.0748 \\
(0.199)\end{array}$ & $\begin{array}{c}-0.00700 \\
(0.0579)\end{array}$ & $\begin{array}{l}0.303 * * * \\
(0.00973)\end{array}$ & $\begin{array}{c}0.0948^{* * *} \\
(0.00291)\end{array}$ & $\begin{array}{c}1.483 * * * \\
(0.159)\end{array}$ & $\begin{array}{c}0.443 * * * \\
(0.0481)\end{array}$ \\
\hline Constant & $\begin{array}{l}0.025 * * * \\
(0.00940)\end{array}$ & $\begin{array}{c}0.0328 * * * \\
(0.0078)\end{array}$ & $\begin{array}{l}-0.78 * * * \\
(0.0863)\end{array}$ & $\begin{array}{c}-0.634 * * * \\
(0.0624)\end{array}$ & $\begin{array}{l}0.043 * * * \\
(0.00654)\end{array}$ & $\begin{array}{c}0.0494^{* * *} \\
(0.00540)\end{array}$ & $\begin{array}{l}-0.126^{*} \\
(0.0692)\end{array}$ & $\begin{array}{l}-0.0975^{*} \\
(0.0518)\end{array}$ \\
\hline Observations & 4,318 & 4,318 & 304 & 304 & 4,318 & 4,318 & 304 & 304 \\
\hline R-squared & 0.121 & 0.169 & 0.374 & 0.435 & 0.337 & 0.379 & 0.517 & 0.532 \\
\hline
\end{tabular}

Standard errors in parentheses. ${ }^{* * *} p<0.01,{ }^{* *} p<0.05, * p<0.1$ 
Table B2. Relationship between team's performance and the actions units associated to the display of anger and happiness. OLS coefficients reported for goal difference, goals scored and goals conceded in the group (first) stage, and for ranking in the World Cup.

\begin{tabular}{|c|c|c|c|c|c|c|c|c|}
\hline \multirow{3}{*}{ VARIABLES } & (1) & (2) & (3) & (4) & (5) & (6) & (7) & (8) \\
\hline & \multicolumn{2}{|c|}{$\begin{array}{l}\text { Goal difference in } \\
\text { stage } 1\end{array}$} & \multicolumn{2}{|c|}{$\begin{array}{l}\text { Goals scored in } \\
\text { stage } 1\end{array}$} & \multicolumn{2}{|c|}{$\begin{array}{l}\text { Goals conceded in } \\
\text { stage } 1\end{array}$} & \multicolumn{2}{|c|}{ World Cup Ranking } \\
\hline & Binary AU & Continuous AU & Binary AU & $\begin{array}{c}\text { Continuous } \\
\mathrm{AU}\end{array}$ & Binary AU & $\begin{array}{c}\text { Continuous } \\
\text { AU }\end{array}$ & Binary AU & Continuous AU \\
\hline Brow lowerer & 1.958 & 0.217 & 0.273 & 0.00282 & $-1.685 *$ & -0.215 & 2.086 & 0.720 \\
\hline 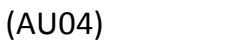 & (1.299) & $(0.347)$ & $(0.810)$ & $(0.216)$ & $(0.906)$ & $(0.242)$ & (2.523) & $(0.674)$ \\
\hline Upper lid raiser & -5.556 & -1.631 & $-7.206 * * *$ & $-2.317^{* * *}$ & -1.650 & -0.687 & $13.29 *$ & 3.593 \\
\hline$(A \cup 05)$ & (3.865) & (1.317) & $(2.410)$ & $(0.821)$ & (2.696) & (0.919) & (7.508) & (2.557) \\
\hline Lid tightener & -0.522 & 0.102 & -1.004 & -0.236 & -0.482 & -0.339 & 0.0974 & -0.664 \\
\hline$(A \cup 07)$ & $(1.481)$ & $(0.487)$ & $(0.923)$ & $(0.303)$ & (1.033) & $(0.340)$ & $(2.876)$ & (0.944) \\
\hline Lip tightener & 1.708 & 0.0385 & -0.217 & -0.0850 & -1.925 & -0.124 & -4.517 & -0.552 \\
\hline$(A \cup 23)$ & $(2.984)$ & (0.969) & $(1.860)$ & (0.604) & (2.081) & $(0.676)$ & $(5.796)$ & $(1.880)$ \\
\hline Cheek raiser & -0.397 & -0.192 & $1.575^{*}$ & 0.354 & $1.972^{*}$ & $0.547^{* *}$ & -4.680 & -0.955 \\
\hline$(A \cup 06)$ & $(1.507)$ & $(0.395)$ & $(0.940)$ & $(0.246)$ & $(1.051)$ & $(0.275)$ & (2.927) & $(0.766)$ \\
\hline Lip corner & 2.110 & 0.539 & $0.305^{\prime}$ & 0.128 & -1.805 & -0.411 & 0.628 & 0.322 \\
\hline puller (AU1 & $(1.954)$ & $(0.600)$ & (1.219) & $(0.374)$ & (1.363) & (0.419) & (3.796) & (1.164) \\
\hline \multirow[t]{2}{*}{ Constant } & -0.907 & -0.576 & $3.816^{* * *}$ & $3.809 * * *$ & $4.723^{* * *}$ & $4.385^{* * *}$ & $9.902 * * *$ & $10.23 * * *$ \\
\hline & (1.183) & (1.052) & $(0.738)$ & $(0.655)$ & $(0.825)$ & $(0.734)$ & $(2.299)$ & $(2.041)$ \\
\hline Observatio & 304 & 304 & 304 & 304 & 304 & 304 & 304 & 304 \\
\hline R-squared & 0.348 & 0.343 & 0.255 & 0.250 & 0.285 & 0.279 & 0.453 & 0.450 \\
\hline
\end{tabular}

Controls included: fraction of participations in World Cup per team, whether team pictures were taken in a studio, whether the team was seeded, confederation and World Cup fixed effects. Standard errors in parentheses. ${ }^{* * *} p<0.01, * * p<0.05, * p<0.1$ 